\title{
Basic research, openness, and convergence
}

\section{Journal Article}

\section{Author(s):}

Gersbach, Hans; Schneider, Maik T.; Schneller, Olivier

Publication date:

2013-03

Permanent link:

https://doi.org/10.3929/ethz-b-000061022

\section{Rights / license:}

In Copyright - Non-Commercial Use Permitted

\section{Originally published in:}

Journal of Economic Growth 18(1), https://doi.org/10.1007/s10887-012-9082-9 


\title{
Basic research, openness, and convergence
}

\author{
Hans Gersbach • Maik T. Schneider • Olivier Schneller
}

Published online: 19 August 2012

(C) Springer Science+Business Media, LLC 2012

\begin{abstract}
We study a model where economic growth is fueled by public basic-research investment and the importation of leading technology from foreign countries. In each period, the government chooses the amount of basic research, balancing the costs and benefits of stimulating growth through both channels. We establish the existence of steady states and the long-run share of technologically advanced sectors in the economy. Then we explore how different degrees of openness affect long-term incentives to invest in basic research. Our main insight is that higher openness tends to encourage more investment in basic research, which, in turn, yields a larger share of leading sectors. If, however, there are prospects of importing major technology advances, highly open countries will reduce basic research as such imports become particularly valuable.
\end{abstract}

Keywords Basic research - Openness $\cdot$ Economic growth

JEL Classification $\mathrm{O} 31 \cdot \mathrm{O} 38$

\section{Introduction}

Policy-makers in industrialized countries often face subtle tradeoffs when they try to foster economic growth. For instance, should a country foster domestic innovations by investing in basic research, or should it rely on potential market entry by foreign firms with superior technology? This is the question addressed in this paper.

We develop a model in which government investments that take the form of employing skilled labor for basic research can foster the innovation success of domestic firms.

H. Gersbach $(\varangle) \cdot$ M. T. Schneider · O. Schneller

Center of Economic Research at ETH Zurich (CER-ETH), 8092 Zurich, Switzerland

H. Gersbach

CEPR, London, UK 
Successful domestic firms are able to produce as monopolists at the technological frontier for a certain time and may drive foreign firms out of the market. In sectors where domestic firms fail to innovate, foreign firms may enter with leading technology. The likelihood of this event depends on the degree of openness.

In such a model, higher investment in basic research for a particular generation has three effects on the economy. First, basic research draws skilled labor from the production sector, thereby making skilled labor more costly and reducing consumption. Second, as basic research fosters innovation, it has a positive effect on the productivity and consumption level of the economy. And third, by increasing innovation success basic research also helps to prevent foreign entry, thereby raising innovation rents and income.

Our results are twofold. First, we establish the circumstances under which the economy converges to a steady state with a particular share of leading industries. In the long run, economies typically either exhibit a constant share of technologically advanced sectors or they converge to polar cases with only leading sectors or none at all.

Second, we examine how changes in the degree of openness affect the optimal level of basic research in the steady states and whether changes in openness foster a country's convergence towards the world's technological frontier. We show that for small and intermediate innovation steps, an increase in openness induces higher investments in basic research which, in turn, yields a higher share of leading sectors in the economy in the long run. The reason is that the benefits of foreign entry arising from the importation of leading technology are smaller than the costs of foreign entry in terms of the domestic firm's profit losses. However, if innovation steps are large, implying that the technological progress induced by foreign entry is large, we observe the opposite relationship.

Our paper is related to theoretical literature that incorporates basic research into R\&Ddriven growth models (e.g. Arnold 1997; Cozzi and Galli 2009, 2011a,b; Gersbach et al. 2009). Most of these contributions focus on the optimal level of basic research in closed economies. There are two papers that also investigate the impact of openness. In a two-country model, Park (1998) analyzes how cross-country knowledge spillovers affect the optimal level of public basic research, whereas the degree of openness determines how large the spillovers are. Our notion of openness differs, as we focus on market entry by foreign firms. Gersbach et al. (2010) study how openness affects the interplay between basic and applied research in a static model. Our paper shows that, in the long run, the correlation between the degree of openness and basic-research investments is positive for moderate technology advances but may be reversed for large technology advances.

Our paper is structured as follows: In the next section we present empirical observations supporting our central model assumptions concerning basic research provision and its impact on private R\&D. In Sect. 3 we present the model. Section 4 is a discussion of the effects of basic research. In Sect. 5 we explore the dynamics of the model, derive the steady states, and characterize their properties, followed by an analysis on the impact of openness in Sect. 6. In Sect. 7 we explore extensions of the basic model and then provide empirical support for our main theoretical findings in Sect. 8. Section 9 concludes.

\section{Empirical observations}

In this section we motivate our assumptions that basic research is largely publically financed and increases the productivity of private $R \& D$ by several empirical observations. 
Table 1 R\&D expenditures

\begin{tabular}{|c|c|c|c|c|c|c|}
\hline & \multicolumn{2}{|c|}{$\begin{array}{l}\text { Gross domestic } \\
\text { expenditures on R\&D as a } \\
\text { percentage of GDP }\end{array}$} & \multicolumn{2}{|c|}{$\begin{array}{l}\text { Basic research } \\
\text { expenditures as a } \\
\text { percentage of total } \\
\text { R\&D expenditures }\end{array}$} & \multicolumn{2}{|c|}{$\begin{array}{l}\text { Applied research } \\
\text { expenditures as a } \\
\text { percentage of total } \\
\text { R\&D expenditures }\end{array}$} \\
\hline & 2000 & 2009 & 2000 & 2009 & 2000 & 2009 \\
\hline Argentina & 0.44 & $0.51^{b}$ & 27.75 & $29.32^{\mathrm{b}}$ & 72.25 & $70.68^{b}$ \\
\hline Australia & 1.47 & $2.24^{\mathrm{c}}$ & 25.81 & $20.03^{\mathrm{c}}$ & 74.19 & $79.97^{\mathrm{c}}$ \\
\hline China & 0.90 & 1.70 & 5.22 & 4.66 & 94.78 & 95.34 \\
\hline Czech Republic & 1.17 & 1.48 & 23.34 & 27.10 & 76.66 & 72.90 \\
\hline France & 2.15 & 2.26 & 23.60 & 26.01 & 76.40 & 73.99 \\
\hline Hungary & 0.81 & 1.17 & 24.24 & 20.62 & 75.76 & 79.38 \\
\hline Ireland & $1.09^{\mathrm{d}}$ & 1.74 & $15.84^{\mathrm{d}}$ & 23.16 & $84.16^{\mathrm{d}}$ & 76.84 \\
\hline Israel & 4.27 & 4.46 & 17.16 & 13.69 & 82.84 & 86.31 \\
\hline Japan & 3.04 & 3.36 & 12.38 & 12.46 & 87.62 & 87.54 \\
\hline Korea & 2.30 & 3.56 & 12.61 & 18.06 & 87.39 & 81.94 \\
\hline Portugal & 0.73 & 1.64 & 22.85 & 18.93 & 77.15 & 81.07 \\
\hline Singapore & 1.85 & 2.27 & 11.75 & 20.28 & 88.25 & 79.72 \\
\hline Slovak Republic & 0.65 & 0.48 & 22.77 & 40.80 & 77.23 & 59.20 \\
\hline Switzerland & 2.53 & $2.99^{\mathrm{c}}$ & 27.96 & $26.78^{c}$ & 72.04 & $73.22^{\mathrm{c}}$ \\
\hline United States & 2.71 & 2.90 & 15.95 & 18.92 & 84.05 & 81.08 \\
\hline Average & 1.74 & 2.18 & 19.28 & 21.39 & 80.72 & 78.61 \\
\hline
\end{tabular}

Source: own calculations based on OECD (2012), Main Science and Technology Indicators

The data has been downloaded in April 2012

a The OECD categorizes R\&D into "basic research", "applied research", "experimental development" and "not elsewhere classified". We summarize the last three items under "applied research"

b Data from 2007

c Data from 2008

d Data from 2002

\subsection{Basic and applied research expenditures}

Basic and applied research expenditures are significant in most industrialized and industrializing countries. As displayed in Table 1, in 2009 the average ratio of total R\&D expenditures to GDP in a sample of countries with comparable data was $2.18 \%$. Besides Israel, R\&D expenditures are highest in the Asian countries Korea and Japan. On average, basic research expenditures amount to $21.39 \%$ of total R\&D expenditures in 2009 . Several smaller countries display higher shares than major industrial countries (US, France or Japan), while China has the lowest share. The average share of basic research expenditures in total R\&D expenditures increased from $19.28 \%$ in 2000 to $21.39 \%$ in 2009.

\subsection{Modes of performance and financing}

Table 2 illustrates that basic research is mainly performed in the public sector, while applied research is carried out mainly by the private sector. This table displays where basic and applied research in 2009 is carried out, broken down into government and higher education institutions, business enterprises, as well as private non-profit institutions. Table 2 indicates that 
Table 2 Basic and applied research by sector of performance in 2009

\begin{tabular}{|c|c|c|c|c|c|c|}
\hline & \multicolumn{3}{|c|}{$\begin{array}{l}\text { Basic research performing shares } \\
\text { (\% of total basic research expenditures) }\end{array}$} & \multicolumn{3}{|c|}{$\begin{array}{l}\text { Applied research performing shares (\% of } \\
\text { total applied research expenditures })^{\mathrm{a}}\end{array}$} \\
\hline & $\begin{array}{l}\text { Government } \\
\text { and higher } \\
\text { education }\end{array}$ & $\begin{array}{l}\text { Business } \\
\text { enterprise }\end{array}$ & $\begin{array}{l}\text { Private } \\
\text { non-profit }\end{array}$ & $\begin{array}{l}\text { Government } \\
\text { and higher } \\
\text { education }\end{array}$ & $\begin{array}{l}\text { Business } \\
\text { enterprise }\end{array}$ & $\begin{array}{l}\text { Private } \\
\text { non-profit }\end{array}$ \\
\hline Argentina & $95.21^{\mathrm{b}}$ & $2.48^{\mathrm{b}}$ & $2.31^{b}$ & $56.36^{\mathrm{b}}$ & $41.91^{\mathrm{b}}$ & $1.73^{b}$ \\
\hline Australia & $77.45^{\mathrm{c}}$ & $16.89^{\mathrm{c}}$ & $5.66^{\mathrm{c}}$ & $25.64^{\mathrm{c}}$ & $72.47^{\mathrm{c}}$ & $1.89^{\mathrm{c}}$ \\
\hline China & 98.37 & 1.63 & 0.00 & 23.28 & 76.72 & 0.00 \\
\hline Czech Republic & 90.02 & 9.65 & 0.33 & 17.25 & 82.19 & 0.57 \\
\hline France & 83.51 & 14.45 & 2.05 & 20.77 & 78.32 & 0.90 \\
\hline Hungary & 87.63 & 12.37 & 0.00 & 28.26 & 71.74 & 0.00 \\
\hline Ireland & 81.30 & 18.70 & 0.00 & 18.80 & 81.20 & 0.00 \\
\hline Israel & 67.22 & 27.32 & 5.46 & 8.67 & 88.54 & 2.79 \\
\hline Japan & 56.89 & 40.62 & 2.50 & 17.75 & 80.76 & 1.49 \\
\hline Korea & 42.26 & 56.64 & 1.10 & 20.10 & 78.14 & 1.75 \\
\hline Portugal & 75.71 & 3.63 & 20.66 & 35.06 & 59.32 & 5.63 \\
\hline Singapore & 67.51 & 32.49 & 0.00 & 30.95 & 69.05 & 0.00 \\
\hline Slovak Republic & 97.86 & 2.09 & 0.04 & 25.03 & 74.92 & 0.05 \\
\hline Switzerland & $71.59^{\mathrm{c}}$ & $23.71^{\mathrm{c}}$ & $4.70^{\mathrm{c}}$ & $7.83^{\mathrm{c}}$ & $91.71^{\mathrm{c}}$ & $0.46^{\mathrm{c}}$ \\
\hline United States & 68.34 & 19.46 & 12.20 & 14.98 & 82.47 & 2.55 \\
\hline Average & 77.39 & 18.81 & 3.80 & 23.38 & 75.30 & 1.32 \\
\hline
\end{tabular}

Source: own calculations based on OECD (2012)

The data has been downloaded in April 2012

a As in Table 1 we summarize the OECD's notions of "applied research", "experimental development" and "not elsewhere classified" under "applied research"

b Data from 2007

c Data from 2008

on average $77.39 \%$ of basic research expenditures were performed by the government and higher education institutions, while business enterprises and private non-profit institutions accounted for 18.81 and $3.80 \%$, respectively. Almost the reverse pattern holds for applied research. On average government and higher education institutions performed $23.38 \%$ of applied research, while the dominant part of $76.62 \%$ is carried out by private institutions (mainly business enterprises). We further know from own calculations based on OECD (2012) that approximately $80 \%$ of R\&D performed in the higher-education and government sector is publicly funded. ${ }^{1}$ Since basic research is mainly performed in this sector, we can conclude that basic research is primarily funded publicly.

\section{3 $\mathrm{R} \& \mathrm{D}$ productivity enhancing basic research}

Basic research impacts applied research through a variety of channels (see e.g. Amon 2011): open science (publications, scientific reports, conferences), "embodied knowledge transfer" associated with scientists moving from basic to applied research, collaborative and contracted research ventures, informal interaction between basic and applied researchers, joint industry-

\footnotetext{
1 The data has been downloaded in May 2012.
} 
university research centers, academic consulting, the patenting and licensing of university inventions, or through the creation of new firms as start-ups and spin-offs from universities.

Various studies have shown that basic research has a positive impact on applied research. For instance Nelson (1986, 2012); Jaffe (1989), Adams (1990); Acs et al. (1992), or Mansfield (1991, 1995, 1998) find a significant and positive impact of academic research on innovative activity and success across various industries. Likewise, Grilliches (1986) identifies that basic research is the most important productivity-growth enhancing component of total R\&D. Furthermore, Acs et al. (1994) and Link and Rees (1990) find that, in particular, small firms benefit relatively strongly from university research. We will therefore model basic research as investments by the government that enhance the productivity of private R\&D.

\section{The model}

Our model stands in the tradition of growth models with quality-improving innovations (Aghion and Howitt 1992). We consider a dynamic set-up with discrete time periods, $t=$ $0,1,2, \ldots$ There is a continuum with measure $1+\bar{L}$ of households, each living for one period, enjoying strictly increasing utility in consumption, and receiving an equal share of the intermediate firms' profits. A measure 1 of the households inelastically supplies one unit of unskilled labor, and a measure $\bar{L}$ of the households supplies skilled labor. Unskilled labor is used in final good production only, while skilled labor is necessary in intermediate good production and basic-research activities. There is no population growth. In each period, a government representing the current generation maximizes the well-being of its citizens by publicly providing basic research financed by an income tax. ${ }^{2}$ We first describe the production side of the economy in a typical period and then proceed to solve the government's optimization problem. In general, we omit the time index $t$, as long as there is no possibility of confusion.

\subsection{Final-good sector}

In the final-good sector, a continuum of competitive firms produces the homogeneous consumption good $y$ according to

$$
y=L_{u}^{1-\alpha} \int_{0}^{1}(A(i) x(i))^{\alpha} d i .
$$

$x(i)$ stands for the amount of intermediate input of variety $i, A(i)$ is this variety's productivity factor, and $L_{u}$ denotes the amount of unskilled labor. The parameter $\alpha$ determines the output elasticity of the intermediate goods or the level of technology. The price of the final consumption good is normalized to one. In the following, we operate with one representative final-good firm that acts competitively. The final-good producer maximizes profits $\pi_{y}$

$$
\max _{\{x(i)\}_{i=0}^{1}, L_{u}}\left\{\pi_{y}=y-\int_{0}^{1} p(i) x(i) d i-w_{u} L_{u}\right\},
$$

\footnotetext{
${ }^{2}$ Essentially, we have a non-overlapping generations model in which each generation elects a government to provide public goods (here basic research) to maximize its well-being. This is equivalent to maximizing the consumption of the current generation.
} 
where $p(i)$ is the price of $\operatorname{good} i$ and $w_{u}$ denotes the wage rate of unskilled labor. The maximization yields the inverse demand for unskilled labor

$$
w_{u}=(1-\alpha) L_{u}^{-\alpha} \int_{0}^{1}(A(i) x(i))^{\alpha} d i .
$$

As unskilled labor is only used in final-good production and its supply is fixed at measure 1, we obtain $w_{u}=(1-\alpha) y$ for the aggregate labor income of unskilled labor. Further, using that the market for unskilled labor clears and thus $L_{u}=1$, we obtain the inverse demand functions for intermediate goods $i$ as

$$
p(i)=\alpha A(i)^{\alpha} x(i)^{\alpha-1} .
$$

We note that the profit of the final-good producer is zero.

\subsection{Intermediate-goods sectors}

Intermediate goods $i$ are produced by skilled labor $L_{x}(i)$ only, using a linear technology:

$$
x(i)=L_{x}(i) .
$$

Each variety $i$ is produced by an intermediate firm. An intermediate-goods firm acts competitively in the market for skilled labor and is a monopolist in its intermediate sector. Profits are given by $p(i) x(i)-w x(i)$, where $w$ denotes the wage level for skilled labor. Accordingly, the monopolistic intermediate firm asks a price $p(i)=\frac{w}{\alpha}$ for its goods, leading to a skilled labor demand of

$$
L_{x}(i)=\left(\frac{\alpha^{2} A(i)^{\alpha}}{w}\right)^{\frac{1}{1-\alpha}}=x(i)
$$

and profits

$$
\pi_{x}(i)=(1-\alpha)\left(\frac{\alpha^{1+\alpha} A(i)^{\alpha}}{w^{\alpha}}\right)^{\frac{1}{1-\alpha}} .
$$

\subsection{Technological state, innovation, and foreign entry}

We follow Aghion et al. (2009) and assume that there is a world technological frontier which in period $t$ is given by $\bar{A}_{t}$ and grows exogenously over time in accordance with

$$
\bar{A}_{t}=\tilde{\gamma} \bar{A}_{t-1},
$$

where $\bar{A}_{t-1}$ denotes the technological frontier of the preceding period and $\tilde{\gamma}>1$. In order to simplify the exposition and the notation, we use $\gamma:=\widetilde{\gamma}^{\frac{\alpha}{1-\alpha}}$ in the remainder of the paper, which yields $\bar{A}_{t}=\gamma^{\frac{1-\alpha}{\alpha}} \bar{A}_{t-1}$.

We assume that each intermediate sector comprises a single domestic firm. At the end of the preceding period, each domestic intermediate firm can be of two types:

Type 1 The firm's technology is on a par with the current technological frontier, $A_{t-1}(i)=$ $\bar{A}_{t-1}$.

Type 2 The firm's technology lags one step behind the current technological frontier, $A_{t-1}(i)=\bar{A}_{t-2}$. 
An intermediate firm innovates with a certain probability. An innovation by a type 1 firm increases the firm's technology level by a factor $\gamma^{\frac{1-\alpha}{\alpha}}$, thus enabling it to retain its position at the technological frontier. Additionally, an innovation by a lagging type 2 firm can enable the firm to leapfrog to the technology frontier.

The government can foster the innovation opportunities of domestic firms by investing in basic research. We specify the probabilities of type 1 and type 2 firms innovating successfully as

$$
\begin{gathered}
\rho_{1}\left(L_{B}\right)=\min \left\{\theta L_{B}, 1\right\}, \\
\rho_{2}\left(L_{B}\right)=\min \left\{\eta \theta L_{B}, 1\right\},
\end{gathered}
$$

where $\theta>0$ and $0<\eta<1$ are parameters that capture the efficiency of basic research with respect to a type 1 firm and leapfrogging by a type 2 firm, respectively. $L_{B}$ denotes the amount of skilled labor in the basic-research sector financed by the government. Equations (6) and (7) specify that basic research constitutes a public good from which domestic intermediate firms can benefit. Throughout the paper, we assume that $L_{B} \leq \frac{1}{\theta}$. This assumption enables us to ignore the kinks in (6) and (7) and to write $\rho_{1}\left(L_{B}\right)=\theta L_{B}$ and $\rho_{2}\left(L_{B}\right)=\eta \theta L_{B}$. As more investments in basic research than $\frac{1}{\theta}$ cannot increase the innovation success of type 1 firms, this assumption is not very restrictive and substantially simplifies the exposition.

In this paper, we focus on the impact of basic research on innovation activities by firms and do not explicitly model applied research activities by firms. Hence probabilities $\rho_{1}\left(L_{B}\right)$ and $\rho_{2}\left(L_{B}\right)$ must be interpreted as the differential impact basic research has on the success of private firms' innovations. For simplicity, we normalize the probability of success to zero if no basic-research capacities are provided by the government. ${ }^{3}$

A type 2 firm that does not innovate successfully has the option of adopting the mature technology, i.e. the technological level that lags one step behind frontier technology. In our model, a type 2 firm currently holding a monopoly position and being unsuccessful in leapfrogging will find it profitable to adopt the next technology. Adopting the next technology will enable a type 2 firm to maintain its monopoly position unless-as we will see subsequently — a foreign firm with a superior technology enters the market. ${ }^{4}$

Openness is introduced in the following way:

- If the domestic firm lags behind the technological frontier, a foreign firm will enter with probability $\sigma$, will introduce the leading technology into the domestic market and will capture the entire market in this sector.

- If the domestic firm produces at the technological frontier, no foreign entry will occur in the respective sector.

Two interpretations of this concept of openness are provided in Appendix B. The property that firms headquartered in a foreign country have superior technology if they manage to enter the domestic market reflects a common finding in the empirical literature indicating that foreign direct investment by leading-edge companies is a powerful mechanism for raising productivity in host countries (e.g Baily and Gersbach 1995; Keller and Yeaple 2009, or

\footnotetext{
3 The qualitative results remain unchanged if we employ $\rho_{1}=\min \left\{\theta L_{B}+\rho_{A}, 1\right\}$ and $\rho_{2}=$ $\min \left\{\eta \theta L_{B}+\rho_{A}, 1\right\}$ with $\rho_{A}$ being the innovation chances of private firms if there is no basic research. A more detailed discussion on how to endogenize private, applied R\&D can be found in Sect. 7.3 and Appendix D.

4 This behavior is often justified by small but positive adoption costs. Such costs prevent potential competitors from investing in technology adoption, as the costs could not be recovered in the ensuing price competition in the specific intermediate sector. We neglect these costs in the analysis. If they were substantial, basic research might have further beneficial effects, as it can lower the costs of adopting mature technologies for domestic firms.
} 
Alfaro et al. 2010). FDI contributes directly to higher levels of productivity by transferring the best production techniques to the host country and indirectly by putting pressure on the host country's domestic producers to improve. ${ }^{5}$

We note that a higher degree of openness in our paper implies a higher probability that leading technology is brought in by foreign firms, but it has no effect on the domestic firms' ability to adopt technology from the world technology frontier. This reflects the idea that new technological products require specific knowledge to be produced. This knowledge is brought in by foreign firms as the empirical literature above indicates. In Sect. 7.5, we discuss how our model can be extended to a concept of openness that additionally includes direct technological spillovers to domestic firms.

In sum, each intermediate sector is in one of three states at the beginning of a particular period:

State 1 Type 1 firm holding a monopoly

State 2 Type 2 firm holding a monopoly

State f Foreign firm with frontier technology holding a monopoly

We denote the fractions of the states in period $t$ by $s_{1, t}$ (state 1), $s_{2, t}$ (state 2), and $s_{f, t}$ (state f), where for all $t, s_{1, t}, s_{2, t}, s_{f, t} \geq 0$ and $s_{1, t}+s_{2, t}+s_{f, t}=1$.

The way the sector states evolve depends on domestic innovation and foreign entry. If the domestic firms in sectors of state 1 or 2 innovate successfully, they will remain in state 1 or move up to state 1 , respectively. If those firms fail to innovate, a foreign firm will enter and take over those sectors with probability $\sigma$. Thus, unsuccessful domestic firms achieve state 2 with the complementary probability $(1-\sigma)$.

If a sector is in state $f$ at the beginning of a particular period, it is possible for the domestic laggard to leapfrog and regain the monopoly position by innovating successfully. ${ }^{6}$ If there is no domestic innovation in the sector, the sector will remain occupied by a foreign firm, given that an innovating foreign firm will find it optimal to introduce the new technology with probability $\sigma$. This may either be the firm that has already occupied the domestic sector if it is able to keep up with the technological frontier or a new foreign firm replacing the old. Hence, with the complementary probability $(1-\sigma)$ the sector is handed back to the domestic laggard. ${ }^{7}$

\subsection{Summary: sequences of events and sector dynamics}

It is useful at this point to summarize the model's timing of events and sector dynamics. In each sector there is one domestic firm that conducts research with success probability $\rho_{1}\left(L_{B}\right)$ if it is currently operating at the technological frontier and $\rho_{2}\left(L_{B}\right)$ if it is lagging behind or the respective sector is occupied by a foreign firm. In each period the following sequence of events occurs:

1. Government chooses basic research

2. Domestic firms conduct $R \& D$

3. Technological frontier increases to $\bar{A}_{t}=\gamma^{\frac{1-\alpha}{\alpha}} \bar{A}_{t-1}$

\footnotetext{
5 The most prominent examples are the US transplants of automotive companies headquartered in Japan.

6 An alternative way of motivating how domestic firms can drive the foreign firm out of the market is to think of spin-offs. There are several empirical studies (e.g. Bania et al. (1993) and Zucker et al. (1998)) that provide evidence that basic research has a positive effect on the creation of new firms. So the innovation probability of type 2 firms could also be understood as the spin-off probability of domestic high-tech firms.

7 An interpretation of this behavior can be found in Appendix B.
} 
4. Domestic firms with technology level $\bar{A}_{t-2}$ failing to innovate and catch-up to frontier level $\bar{A}_{t}$ adopt a mature technology at the level $\bar{A}_{t-1}$

5. Foreign firms decide whether to enter (or keep on operating in) the domestic market

6. Production of consumption good

The following remark is in order here. Due to their public-good characteristics, investments in basic research constitute aggregate expenditures and benefit all sectors. As an individual firm in one sector cannot generate aggregate profits in the continuum of sectors, it will not be able to produce a positive amount of basic research itself.

In Appendix $\mathrm{C}$ we provide an alternative micro-foundation of our set-up with multiple domestic firms and patent races. ${ }^{8}$ The following scheme illustrates the sector dynamics within a period:

$$
\begin{gathered}
s_{1, t-1} \longrightarrow\left\{\begin{array}{cl}
\rho_{1} & : s_{1, t} \\
\left(1-\rho_{1}\right) \sigma & : s_{f, t} \\
\left(1-\rho_{1}\right)(1-\sigma) & : s_{2, t}
\end{array}\right. \\
s_{2, t-1} \longrightarrow\left\{\begin{array}{cl}
\rho_{2} & : s_{1, t} \\
\left(1-\rho_{2}\right) \sigma & : s_{f, t} \\
\left(1-\rho_{2}\right)(1-\sigma) & : s_{2, t}
\end{array}\right. \\
s_{f, t-1} \longrightarrow\left\{\begin{array}{cc}
\rho_{2} & : s_{1, t} \\
\left(1-\rho_{2}\right) \sigma & : s_{f, t} \\
\left(1-\rho_{2}\right)(1-\sigma) & : s_{2, t}
\end{array}\right.
\end{gathered}
$$

Accordingly, we obtain the following equations of motion for the country's industry structure:

$$
\begin{aligned}
& s_{1, t}=s_{1, t-1} \theta L_{B}+\left(1-s_{1, t-1}\right) \eta \theta L_{B}, \\
& s_{2, t}=(1-\sigma)\left[\left(1-\theta L_{B}\right) s_{1, t-1}+\left(1-\eta \theta L_{B}\right)\left(1-s_{1, t-1}\right)\right], \\
& s_{f, t}=\sigma\left[\left(1-\theta L_{B}\right) s_{1, t-1}+\left(1-\eta \theta L_{B}\right)\left(1-s_{1, t-1}\right)\right] .
\end{aligned}
$$

\subsection{Equilibrium}

The economy comprises the market for the final consumption good with price unity, the market for skilled labor with wage rate $w$, the market for unskilled labor with wage rate $w_{u}$, and a continuum of intermediate-goods markets with prices $p(i)=\frac{w}{\alpha}$. As unskilled labor is only used in final-good production and has a fixed supply of measure 1, the wage rate $w_{u}$ is defined as in Sect. 3.1. In the skilled labor market, labor $\bar{L}$ is supplied inelastically. Demand for skilled workers consists of the government's demand for basic researchers and the demand for skilled workers in intermediate-goods production. Hence the market for skilled labor clears when

\footnotetext{
8 Another reasonable assumption would be that the laggard type 2 sectors are perfectly competitive because all firms can adopt the lagging technology level for free. Changing the model set-up in this direction poses no problems. It is slightly less convenient with respect to the mathematical calculations and adds one additional effect: the Monopoly Distortion Effect. If a type $1 \mathrm{firm}$ is not successful in its innovation project to keep up with the technological frontier, the sector will become perfectly competitive, and consequently the monopoly distortion will vanish. Hence, in contrast to our standard formulation, basic research not only promotes productivity gains but also monopoly distortions. As a consequence, the incentive to invest in basic research would be lower.
} 


$$
\bar{L}=L_{B}+\int_{0}^{1} L_{x}(i) d i .
$$

The demand for skilled workers in intermediate-goods production depends on the sector's technological level after innovation activities and foreign entry have occurred. This reflects our assumption that foreign intermediate firms bring leading technology with them from abroad but produce the intermediate goods within the country. Consequently, the total intermediates' demand for skilled production workers is given by

$$
\int_{0}^{1} L_{x}(i) d i=\left(s_{1, t}+s_{f, t}\right) L_{1, x}+s_{2, t} L_{2, x} .
$$

The variable $L_{1, x}$ denotes the skilled labor demand in a technologically leading sector with the technology level $\bar{A}_{t}$ and $L_{2, x}$ the skilled labor demand in a technologically lagging sector with the technology level $\bar{A}_{t-1}$ given by Eq. (4). Using Eq. (4), we can rewrite (12) as

$$
\begin{aligned}
\int_{0}^{1} L_{x}(i) d i & =\left(\frac{\alpha^{2} \bar{A}_{t}^{\alpha}}{w}\right)^{\frac{1}{1-\alpha}} \chi\left(L_{B}\right), \text { where } \\
\chi\left(L_{B}\right) & =s_{1, t}+s_{f, t}+s_{2, t} \frac{1}{\gamma} .
\end{aligned}
$$

Note that according to the system dynamics given in (8)-(10), $\chi\left(L_{B}\right)$ is a linear function of $L_{B}$. Therefore it is convenient to define $\chi\left(L_{B}\right)=\chi^{\prime} L_{B}+\bar{\chi}$. Inserting (13) into (11) we obtain the equilibrium wage for skilled labor for a given level of basic research:

$$
w\left(L_{B}\right)=\alpha^{2} \bar{A}_{t}^{\alpha}\left[\frac{\chi\left(L_{B}\right)}{\bar{L}-L_{B}}\right]^{1-\alpha} .
$$

An increase in basic research has two effects on the wage level for skilled labor. First, a higher technological level increases the productivity of the respective intermediates and consequently enhances demand. This leads to a wage increase. Second, by reducing the supply of skilled labor for intermediate good production, a rise in $L_{B}$ also increases the wage level. The following lemma formalizes the effect of basic research on the equilibrium wage for skilled labor:

Lemma $1 \frac{d w\left(L_{B}\right)}{d L_{B}}>0$.

Proof See Appendix A.1.

From the equilibrium wage for skilled labor we obtain the equilibrium prices for intermediate goods, from which the quantities, the firms' profits, and the wage for unskilled labor in equilibrium follow. To simplify notation, we will henceforth use $w$ to denote the equilibrium wage for skilled labor associated with a particular level of basic research.

\subsection{Government}

In each period, the government chooses the amount of basic-research labor $L_{B}\left(L_{B}<\bar{L}\right)$ required to maximize aggregate consumption $c$ by the current generation. The expenditures $w L_{B}$ are financed by a tax $\tau \in[0,1]$ on household income. Households earn wages and obtain 
profits from domestic intermediate-goods production. Consequently, the budget constraint for the government reads

$$
w L_{B}=\tau\left(w \bar{L}+w_{u}+s_{1, t} \pi_{1, x}+s_{2, t} \pi_{2, x}\right),
$$

where $\pi_{1, x}$ and $\pi_{2, x}$ represent the profits of a technologically leading firm and that of a technologically lagging firm, respectively. Aggregate domestic consumption $c$ equals total income after taxes:

$$
c=(1-\tau)\left(w \bar{L}+w_{u}+s_{1, t} \pi_{1, x}+s_{2, t} \pi_{2, x}\right) .
$$

By using the aggregate income identity, the government's problem can also be written as

$$
\begin{aligned}
\max _{L_{B}}\{c & \left.=y-s_{f, t} \pi_{1, x}\right\} \\
& =\left(\frac{\alpha^{2} \bar{A}_{t}}{w}\right)^{\frac{\alpha}{1-\alpha}}\left[s_{1, t}+s_{2, t} \frac{1}{\gamma}+s_{f, t}(1-\alpha(1-\alpha))\right] .
\end{aligned}
$$

Let us define

$$
\zeta\left(L_{B}\right)=s_{1, t}+s_{2, t} \frac{1}{\gamma}+s_{f, t}(1-\alpha(1-\alpha)) .
$$

The government's objective can now be written as $c=\left(\frac{\alpha^{2} \bar{A}_{t}}{w}\right)^{\frac{\alpha}{1-\alpha}} \zeta\left(L_{B}\right)$. As we know from the equations of motion (8)-(10) that $\zeta\left(L_{B}\right)$ is a linear function of $L_{B}$, we can define $\zeta\left(L_{B}\right)=\zeta^{\prime} L_{B}+\bar{\zeta}$. The following proposition gives the solution to the government's optimization problem:

Proposition 1 The unique solution to the government's maximization problem is given by

$$
\begin{aligned}
& L_{B}=\min \left\{L_{B}^{+}, \frac{1}{\theta}\right\}, \text { if } L_{B}^{+} \in \mathbb{R} \text { and } L_{B}^{+} \geq 0, \\
& L_{B}=0, \text { else, }
\end{aligned}
$$

where

$$
\begin{aligned}
L_{B}^{+} & =\frac{1-\alpha}{2} \bar{L}-\frac{1+\alpha}{2} \hat{\chi}+\sqrt{\left(\frac{1-\alpha}{2} \bar{L}-\frac{1+\alpha}{2} \hat{\chi}\right)^{2}-(\alpha \hat{\zeta}-\hat{\chi}) \bar{L}-\alpha \hat{\zeta} \hat{\chi}}, \\
\hat{\zeta} & =\frac{\bar{\zeta}}{\zeta^{\prime}}, \text { and } \hat{\chi}=\frac{\bar{\chi}}{\chi^{\prime}} .
\end{aligned}
$$

Proof See Appendix A.2.

Note that the optimal level of basic research depends on the economy's share of leading sectors in the previous period because $\hat{\chi}$ and $\hat{\zeta}$ depend on $s_{1, t-1}$. Hence, (20) defines a function $L_{B}^{+}\left(s_{1, t-1}\right)$ and the government's optimal level of basic research as $L_{B}\left(s_{1, t-1}\right)=$ $\max \left\{\min \left\{L_{B}^{+}\left(s_{1, t-1}\right), 1 / \theta\right\}, 0\right\}$, which we will use to analyse the dynamics of the economy. Our model exhibits a distance to frontier effect, as a higher level of $s_{1, t-1}$ tends to support higher investment in basic research $L_{B} .{ }^{9}$

9 See Gersbach et al. (2010) for a detailed analysis of this effect in a static model encompassing both applied and basic research. 


\section{Effects of basic research}

Before turning to comparative statics with respect to a country's openness, we here introduce the different effects of basic-research investment on aggregate consumption. To identify the effects, we will use the derivative of $c$ with respect to $L_{B}$ in Eq. (18):

$$
\begin{aligned}
\frac{d c}{d L_{B}}= & -\frac{\alpha}{1-\alpha}\left(\frac{\alpha^{2} \bar{A}_{t}}{w}\right)^{\frac{\alpha}{1-\alpha}} \frac{1}{w} \frac{d w}{d L_{B}} \zeta\left(L_{B}\right) \\
& +\left(\frac{\alpha^{2} \bar{A}_{t}}{w}\right)^{\frac{\alpha}{1-\alpha}}\left[\frac{d s_{1, t}}{d L_{B}}+\frac{d s_{2, t}}{d L_{B}} \frac{1}{\gamma}+\frac{d s_{f, t}}{d L_{B}}(1-\alpha(1-\alpha))\right] .
\end{aligned}
$$

The first summand reflects the change in consumption caused by the change in the equilibrium wage for skilled labor induced by marginally higher basic-research investment. We refer to this effect as the Labor Cost Effect. From Lemma 1 we infer that this effect is negative. The second summand captures the effect of basic research on the country's industry structure. From the equations of motion (Eqs. (8)-(10)) we obtain

$$
\begin{aligned}
& \frac{d s_{1, t}}{d L_{B}}=s_{1, t-1} \theta(1-\eta)+\theta \eta, \\
& \frac{d s_{2, t}}{d L_{B}}=-(1-\sigma) \frac{d s_{1, t}}{d L_{B}}, \\
& \frac{d s_{f, t}}{d L_{B}}=-\sigma \frac{d s_{1, t}}{d L_{B}} .
\end{aligned}
$$

This reveals that basic research increases the number of domestic sectors operating at the technology frontier and decreases both the number of lagging sectors and the sectors with a foreign technology leader. Inserting the changes in sector sizes, the second summand of (21) can be written as follows:

$$
\left(\frac{\alpha^{2} \bar{A}_{t}}{w}\right)^{\frac{\alpha}{1-\alpha}}\left[s_{1, t-1} \theta(1-\eta)+\theta \eta\right]\left[(1-\sigma)\left(1-\frac{1}{\gamma}\right)+\sigma \alpha(1-\alpha)\right] \text {. }
$$

The term $(1-\sigma)\left(1-\frac{1}{\gamma}\right)$ reflects the positive effect that marginal basic-research investment has on consumption caused by the higher technological level. This reflects the Productivity Effect of basic research. The other term $\sigma \alpha(1-\alpha)$ stands for the Escape Entry Effect. It captures the rise in consumption arising from the fact that the marginal basic-research investment induces some sectors to be held by a domestic technology leader instead of a foreign technology leader. The advantage of a domestic firm over a foreign firm operating at the same technological level, is that profits are retained in the country. We can summarize our findings as follows.

\section{Summary}

A marginal change in basic research has the following three effects on aggregate consumption:

(i) Labor Cost Effect

$$
L C=-\frac{\alpha}{1-\alpha}\left(\frac{\alpha^{2} \bar{A}_{t}}{w}\right)^{\frac{\alpha}{1-\alpha}} \frac{1}{w} \frac{d w}{d L_{B}} \zeta\left(L_{B}\right) .
$$


(ii) Escape Entry Effect

$$
E E=\left(\frac{\alpha^{2} \bar{A}_{t}}{w}\right)^{\frac{\alpha}{1-\alpha}}\left[s_{1, t-1} \theta(1-\eta)+\theta \eta\right] \sigma \alpha(1-\alpha) .
$$

(iii) Productivity Effect

$$
P E=\left(\frac{\alpha^{2} \bar{A}_{t}}{w}\right)^{\frac{\alpha}{1-\alpha}}\left[s_{1, t-1} \theta(1-\eta)+\theta \eta\right](1-\sigma)\left(1-\frac{1}{\gamma}\right) .
$$

The Escape Entry Effect and the Productivity Effect have a positive influence on aggregate consumption, whereas the Labor Cost Effect lowers consumption. For our analysis it is important to see how the level of openness $\sigma$ affects the Escape Entry Effect and the Productivity Effect. As $\sigma$ increases entry threat, the Escape Entry Effect increases with $\sigma$. For the extreme case of $\sigma=0$, implying a closed economy, the Escape Entry Effect vanishes. By contrast, the Productivity Effect decreases with $\sigma$. The reason is that the more open the economy is, the more it will benefit from the high technology of foreign firms. Accordingly, fewer domestic innovations can contribute to technological progress. For the maximum value $\sigma=1$ the economy will feature the frontier technology in every sector, irrespective of how much basic research is performed, so in this case the Productivity Effect is zero.

\section{Dynamics and steady state}

In this section we first characterize the economy's sectoral dynamics and then derive the model's steady state. From the equations of motion (8)-(10) we obtain

$$
s_{2, t}=\frac{1-\sigma}{\sigma} s_{f, t}, \forall t
$$

and

$$
\begin{aligned}
& s_{2, t}=(1-\sigma)\left(1-s_{1, t}\right), \forall t, \\
& s_{f, t}=\sigma\left(1-s_{1, t}\right), \forall t .
\end{aligned}
$$

In other words, the sectors of the economy without a domestic technology leader are split between domestic laggards and foreign technology leaders in accordance with the degree of openness. Consequently, given openness, the industrial structure of the economy in period $t$ is entirely pinned down by the share of sectors occupied by type 1 firms. In this way, the dynamics of the economy are fully determined by the following difference equation:

$$
s_{1, t}=L_{B}\left(s_{1, t-1}\right) \psi\left(s_{1, t-1}\right),
$$

where $\psi\left(s_{1, t-1}\right)=s_{1, t-1} \theta(1-\eta)+\eta \theta$ and $L_{B}\left(s_{1, t-1}\right)$ has been given in Sect. 3.6. As $L_{B}\left(s_{1, t-1}\right)$ is a linear function, we will show that there are two distinct steady-state patterns that may emerge. Either there is a unique and stable steady state, or there exists one unstable steady state and two stable ones. The pattern that occurs depends on the impact of basic research on the innovation success of private firms. A complete characterization of all possible steady-state patterns and associated stability properties is given in Appendix A.3. Here we focus on two particularly interesting cases from an economic viewpoint. 


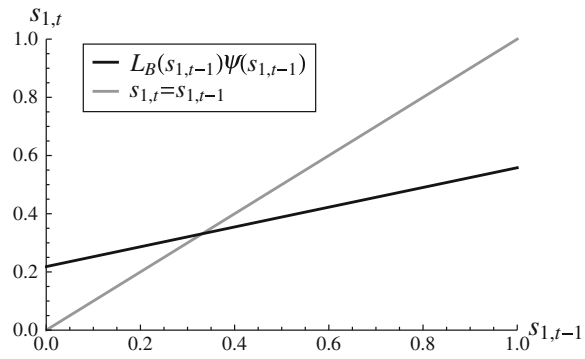

(i)

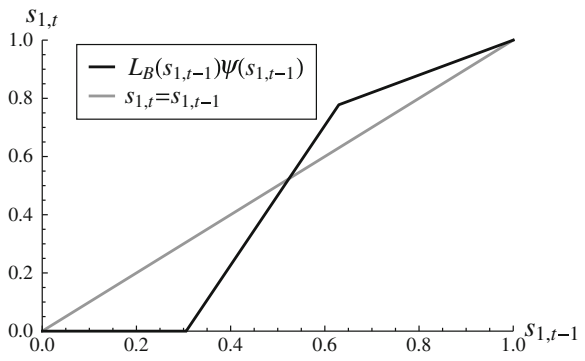

(ii)

Fig. 1 Steady-state patterns

\section{Proposition 2}

(i) If $L_{B}^{+}(0)>0$ and $L_{B}^{+}(1)<\frac{1}{\theta}$, then there exists a unique and stable steady state with $0<s_{1}^{s}<1$.

(ii) If $L_{B}^{+}(0)<0$ and $L_{B}^{+}(1)>\frac{1}{\theta}$, then there exists one interior steady state that is not stable. The stable steady states are given by the two corner solutions $s_{1}^{s}=0$ and $s_{1}^{s}=1$.

Proof See Appendix A.3.

The specific interior steady-state values of the share of state 1 sectors are given by

$$
s_{1}^{s}=\frac{-B \pm \sqrt{B^{2}-4 A C}}{2 A},
$$

where

$$
\begin{aligned}
& A=(1-\alpha) \bar{L} \theta(1-\eta)-1, \\
& B=\bar{L}\left[\theta(1-\eta)\left(\frac{\bar{\chi}}{\tilde{\chi}}-\alpha \frac{\bar{\zeta}}{\tilde{\zeta}}\right)+(1-\alpha) \eta \theta\right]-(1+\alpha) \frac{\bar{\chi}}{\tilde{\chi}}, \\
& C=\eta \theta \bar{L}\left(\frac{\bar{\chi}}{\tilde{\chi}}-\alpha \frac{\bar{\zeta}}{\tilde{\zeta}}\right)-\alpha \frac{\bar{\chi}}{\tilde{\chi}} \frac{\bar{\zeta}}{\tilde{\zeta}}, \\
& \tilde{\zeta}=(1-\sigma)\left(1-\frac{1}{\gamma}\right)+\sigma \alpha(1-\alpha), \\
& \tilde{\chi}=(1-\sigma)\left(1-\frac{1}{\gamma}\right) .
\end{aligned}
$$

Figure 1 illustrates Proposition 2 by plotting the function $s_{1, t}\left(s_{1, t-1}\right)$ as defined by Eq. (26). For each of the two steady-state patterns an example is presented. In case (i), $s_{1, t}\left(s_{1, t-1}\right)$ possesses exactly one fixed point, which constitutes the unique and stable steady state. Case (ii) features three intersections of $s_{1, t}\left(s_{1, t-1}\right)$ with the bisectoral line, of which only the two intersections at the corners are stable. The kink in $s_{1, t}\left(s_{1, t-1}\right)$ is caused by $L_{B}\left(s_{1, t-1}\right)$ reaching the upper bound $\frac{1}{\theta}$.

Note that case (ii) may display a backwardness-trap phenomenon. Countries that are technologically advanced, i.e. that possess a high number of advanced domestic sectors, will converge to the stable steady state that comprises only state 1 sectors, while countries that are less advanced than the steady state level of the unstable fixed point will converge to 
the steady state without any state 1 sectors. As a consequence, the output level in the less advanced country is substantially lower than that of the advanced country, at least if the degree of openness is small. Given that the costs of basic research for the advanced country in the $s_{1}=1$ steady state do not outweigh the output gains relative to the less advanced country in the $s_{1}=0$ steady state, the latter country will find itself in a backwardness trap.

\section{Impact of openness and other parameters}

In this section, we analyze how the steady-state value of basic research denoted by $L_{B}^{s}$ is affected by changes in the degree of openness and other parameters. In addition, we discuss how openness affects the convergence of a country to the technological frontier.

Interior steady states of basic research are given by inserting (27) back into (20). As the steady state level of basic research cannot be derived analytically, we rely on numerical simulations. As a basic scenario, we choose the following set of parameters: $\alpha=0.4, \gamma=$ 1.45, $\theta=2.49, \eta=0.8, \bar{L}=\frac{2}{3}, \bar{A}=100 . \alpha$ specifies the output elasticities of both types of labor. Our choice of $\alpha=0.4$ constitutes an intermediate level of the estimates found in the literature (e.g. Caucutt and Kumar $2003(\alpha=0.5)$ or Blankenau et al. $2007(\alpha=0.2)$ ). $\gamma=1.45$ implies that the economy grows at a rate of $25 \%$ in each period. In our model, basic-research investments are considered for each generation, so it is convenient to think of a period as comprising one or two decades, which generates plausible annual growth rates. ${ }^{10}$ This is also consistent with the fact that basic research exhibits major time lags between investment and its effect on productivity (e.g. Adams 1990 or Mansfield 1998). $\vec{L}=\frac{2}{3}$ is set to reflect the OECD average share of the labor force with tertiary education of roughly $40 \%$ (World Bank 2010). With respect to the technological level we choose the normalization $\bar{A}=100$.

In the light of the large heterogeneity of openness across countries, we choose the intermediate degree of openness $\sigma=0.5$ in order to calibrate $\theta$ and $\eta$ such that we obtain a steady state with $L_{B}^{S} \approx \frac{1}{50}$. ${ }^{11}$ This value reproduces a share of GDP devoted to basic research that is close to $0.5 \%$, which constitutes the average basic research expenditures of highly industrialized countries (OECD 2010). ${ }^{12}$ The basic parametrization features a steady-state pattern as described in Proposition 2 (i).

\subsection{Changes in openness}

\section{Basic scenario}

We start our analysis with a detailed discussion of the effect of openness. Figure 2 depicts how changes in the degree of openness affect the steady-state level of basic research in the basic scenario. We observe that $L_{B}^{S}$ increases with openness and also that a minimal degree of openness is needed to induce a positive level of basic research, i.e. we obtain the corner solu-

\footnotetext{
${ }^{10}$ For example, assuming that one period represents a decade yields an annual growth rate of $2.4 \%$, which equals the average growth rate in the U.S. between the years 1960 and 2000.

${ }^{11}$ Recall that a degree of openness of $\sigma=0.5$ means a probability of 0.5 that a foreign firm enters a lagging sector with leading technology.

12 The connection between $L_{B}^{S} \approx \frac{1}{50}$ and $0.5 \%$ of GDP is as follows: In our model, the expenditures for basic research accrue to $w L_{B}$. Hence, to match a share of $0.5 \%$ of GDP we solve $\frac{w L_{B}}{y}=0.005$ to obtain $L_{B}=\frac{10}{495}$.
} 


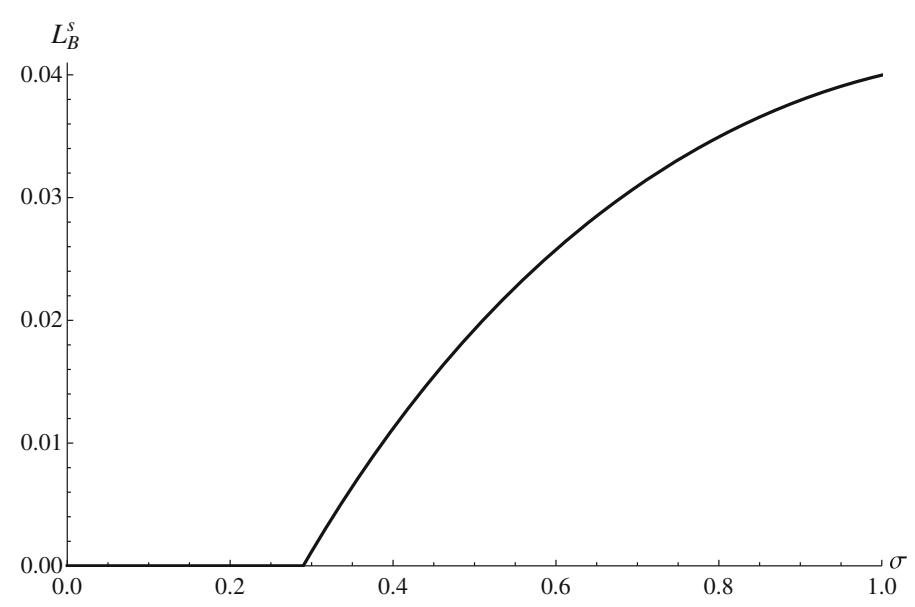

Fig. 2 Effect of openness $\left(\alpha=0.4, \gamma=1.45, \theta=2.49, \eta=0.8, \bar{L}=\frac{2}{3}, \bar{A}=100\right)$

tion $L_{B}^{s}=0$ for low levels of openness. To understand this result, it is instructive to consider the three effects of basic research described in Sect. $4(L C, E E, P E)$. As we saw there, an increasing degree of openness, implying a higher probability of foreign firm entry, makes the Escape Entry Effect stronger and lowers the Productivity Effect. Increasing openness also reduces the negative Labor Cost Effect. The reason is as follows: Basic research increases the skilled labor demand of intermediate firms by fostering technological progress. A higher degree of openness mitigates this demand effect and thus lowers the Labor Cost Effect as the import of leading technology reduces the impact of basic research on the economy's technological level.

Summarizing, we can say that, on the one hand, a rise in openness will increase the incentives to invest in basic research by increasing the positive Escape Entry Effect and decreasing the negative Labor Cost Effect. On the other hand, a rise in the probability of foreign firms entering with leading technology also lowers the investment incentives by decreasing the positive Productivity Effect. In the basic scenario, we obtain a positive relationship between $L_{B}^{S}$ and openness, as $\left|\frac{d L C}{d \sigma}+\frac{d E E}{d \sigma}\right|$ dominates $\left|\frac{d P E}{d \sigma}\right|$. This result can be interpreted in the following way: The government will prefer to prevent foreign entry and keep the intermediate profits in the country instead of benefiting from imported leading technology. As a result, a larger entry threat will induce the government to increase investments in basic research, and a steady state with a higher level of basic research is achieved.

\section{Large technology advances}

From Eq. (25) we observe that innovation step $\gamma$ is a major determinant of the Productivity Effect. The faster the frontier technology grows, the more important is the Productivity Effect, as domestic innovations cause higher technological progress. The way openness affects the economy when we consider larger technology advances is demonstrated in Figure 3. It reveals that in this case we have a negative relationship between openness and steady-state basic research. The reason is that the Productivity Effect is much larger, whereas the levels of the Labor Cost and the Escape Entry Effect are only moderately affected by the rise in $\gamma$. As a result, $\left|\frac{d P E}{d \sigma}\right|$ now dominates $\left|\frac{d L C}{d \sigma}+\frac{d E E}{d \sigma}\right|$ and causes the falling pattern for $L_{B}^{S}$. In this case, implementing the leading technology in the domestic country is more important than 


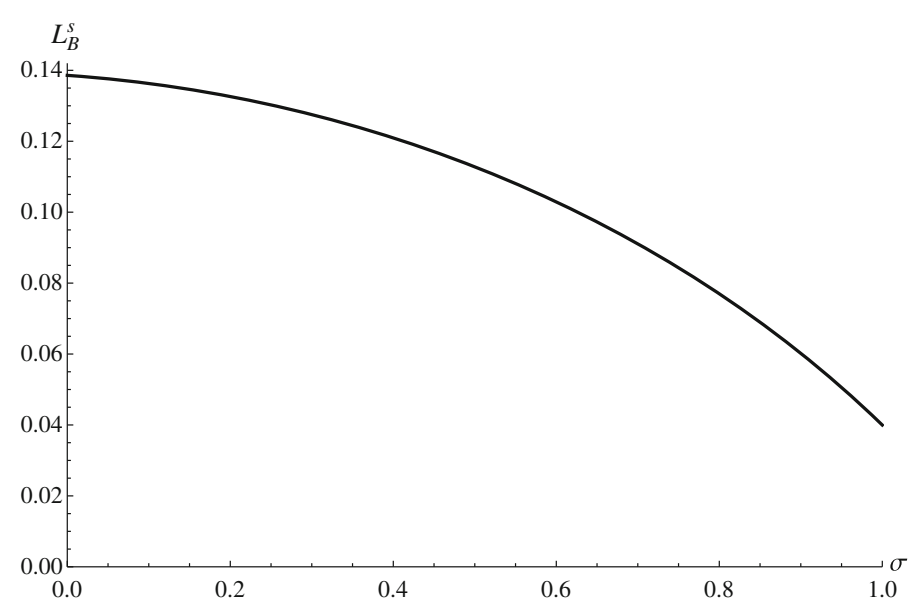

Fig. 3 Effect of openness for high $\gamma\left(\alpha=0.4, \gamma=1.7, \theta=2.48, \eta=0.8, \bar{L}=\frac{2}{3}, \bar{A}=100\right)$

protecting the domestic intermediates' profits. Hence, the entry of foreign firms is welcome, as they implement leading technologies. In other words, to obtain leading technology it is cheaper to allow foreign entry and forgo domestic profits than to draw skilled labor from intermediate-goods production to invest in basic research.

Note that for $\sigma=1$ the basic scenario and the scenario with high technology advances feature the same steady-state level for basic research. Maximum openness implies that all sectors of the domestic economy feature the leading technology, independently of the level of basic research. So there is no Productivity Effect, and the size of $\gamma$ is immaterial for the steady-state level of basic research.

\subsection{Changes in other parameters}

If openness is kept fixed at $\sigma=0.5$, the way the remaining parameters affect steady-state basic research is straightforward and is summarized in Table $3 .{ }^{13}$ A rise of $\alpha$ increases the importance of the intermediate goods in production. As a consequence, the pressure on the market for high-skilled labor increases, which results in lower basic-research investments. We have already indicated in the previous subsection that a rise in $\gamma$ increases the Productivity Effect and yields larger incentives to invest in basic research. Research productivity increases with $\theta$ as well as with $\eta$, which explains the positive relationship between those parameters and $L_{B}^{s}$. The parameter $\theta$ could, for example, reflect the country's level of human capital. Our theory would then imply that countries with higher stocks of human capital invest more in basic research and have a larger share of sectors with technologically leading domestic firms. Note that in this case there are two effects with an impact on higher basic-research investments: (a) a direct effect due to the higher probability of success when $\theta$ is higher, and (b) an indirect effect as the incentive to invest in basic research also increases if the share of $s_{1}$ sectors increases because there are more sectors with success probability $\rho_{1}$ relative to the smaller $\rho_{2}$. So there is also the effect that ceteris paribus optimal basic-research investments

13 We do not examine changes with respect to $\bar{L}$. Such an analysis would require an assumption on scale effects, as it would be necessary to specify $\theta$ as a function of $\bar{L}$. The one extreme would be to assume $\theta(\bar{L})$ to be constant with strong scale effects. The other extreme would be the absence of scale effects by assuming $\theta(\bar{L}) \cdot \bar{L}$ to be constant. 
Table 3 Effect of parameter increases on $L_{B}^{S}$

\begin{tabular}{lllll}
\hline & $\alpha$ & $\gamma$ & $\theta$ & $\eta$ \\
\hline$L_{B}^{S}$ & - & + & + & + \\
\hline
\end{tabular}

are higher, the closer the country is to the technological frontier (measured in terms of the share of leading sectors). ${ }^{14}$

\subsection{Convergence}

What do our results imply for the effect of openness on the convergence of a country to the technological frontier? We can apply two notions of convergence:

(1) A country converges to the technological frontier if the share of intermediates with leading technology increases (i.e., a country's production level comes closer to the output of a technologically advanced country with leading technology in every sector).

(2) A country converges to the technological frontier if the share of intermediates with leading technology produced by domestic firms increases (i.e., the technological knowledge in the country increases).

With respect to the second notion of convergence focussing on the steady-state share of state1 sectors, we can directly infer from the previous results that greater openness will foster convergence if the innovation steps are small and will lead to divergence if the innovation steps are large.

Applying the broader notion of convergence (1) focussing on production output rather than technological knowledge, we come to the same result as under notion (2) if innovation steps are small. Figure 2 shows that increased openness fosters basic-research investments via a strong Escape Entry Effect leading to a higher share of state-1 sectors. In addition, the share of f-sectors with high technology increases as well. Hence the country's output level approaches the highest achievable at the technological frontier.

If innovation steps are large, we obtain an ambiguous result. Here a larger degree of openness leads to a higher share of foreign firms with leading technology but a lower share of domestic firms operating at the frontier. In this scenario, we observe a crowding-out effect with respect to domestic research. Whether or not convergence occurs if openness increases depends on the magnitude of the effects, i.e. whether the share of incoming foreign firms is larger than the loss of domestic technology leaders. In our example setting, illustrated by Fig. 3, basic-research investments do not decline strongly in response to an increased $\sigma$. Hence, the total share of sectors operating with leading technology increases. In this case, the country converges to the technological frontier in terms of production output but diverges in terms of domestic technological knowledge.

\section{Extensions and discussion}

In this section we examine the robustness of our results and explore extensions of the basic model.

14 This replicates the findings of Gersbach et al. (2010) in a dynamic context. 


\subsection{Taxation}

In the basic model we have made two assumptions regarding taxation, (a) uniform income taxation and (b) the inability to tax profits of foreign firms. We first explore the consequences if the first assumption is relaxed.

\section{Alternative income tax schemes}

As every source of income could be taxed differently, we consider in this section an arbitrary income tax system. Formally, let the sources of income or tax bases be denoted by $t b=\left(t b_{1}, t b_{2}, \ldots, t b_{n}\right)$, where $y_{d}=\sum_{j=1}^{n} t b_{j}$ is the aggregate domestic income. Each tax base $t b_{j}$ is taxed at the corresponding rate $\tau_{j} \leq 1$, where we denote the vector of the different tax rates by $\tau=\left(\tau_{1}, \tau_{2}, \ldots, \tau_{n}\right)$. For example, $t b_{1}$ could be labor income taxed at the labor income tax rate $\tau_{1}$, while the (domestic) profits $t b_{2}$ are taxed at rate $\tau_{2}$. Note that some $\tau_{j}$ might be zero and that we also allow them to be negative. Then we obtain for the condition for a balanced budget that $w L_{B}=\tau * t b$ and the objective of the government is to maximize $c=y_{d}-\tau * t b$. Inserting the budget constraint into the objective function, the latter transforms to $c=y_{d}-w L_{B}$, which is identical to (18) for any tax system $(t b, \tau)$.

This shows that within our framework the uniform income tax scheme is equivalent to any other income tax scheme and is thus optimal, given that foreign firms cannot be taxed. Intuitively, the reason is that the households' labor supply is inelastic, so they cannot avoid or reduce their tax burden via endogenous changes in their behavior, such as increasing leisure time relative to work or becoming an entrepreneur rather than a worker.

\section{Taxation of foreign multinational firms}

We have made the assumption that foreign multinational firms cannot be taxed. This is a polar reflection of the ability of multinational firms to reduce their tax burden in a foreign country by transferring costs across subsidiaries. Empirical studies provide evidence that this effect is significant (e.g. Huizinga and Laeven 2008 or Weichenrieder 2009).

We next explore the consequences if taxation of foreign multinational firms entering the domestic market is possible to some extent. We start with the observation that it is always optimal to tax the foreign profits at the highest rate in our model (as such profits do not enter domestic welfare) and to tax domestic income to finance the residual public expenditures for basic research. ${ }^{15}$

Let $\bar{\tau}$ be the highest possible effective tax rate on foreign profits. This upper limit is given by the minimum of tax rates in tax laws, by international tax treaties, and by the abilities of multinationals to reduce their tax burden. As discussed above, it is optimal to tax foreign profits at the highest rate $\bar{\tau}$. Given any tax system on domestic income $(t b, \tau)$ as described

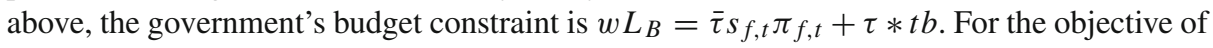
the government we now obtain $c=y_{d}-\tau * t b=y_{d}-w L_{B}+\bar{\tau} s_{f, t} \pi_{f, t}=y-(1-\bar{\tau}) s_{f, t} \pi_{f, t}$. Hence, the negative weight attached to foreign profits in the government's objective becomes lower, as part of the profits can be kept within the country.

Following the same steps as in the analysis in the main text reveals that this extension will reduce the Escape Entry Effect and increase the Labor Cost Effect, while the Productivity

15 If the highest possible tax revenue from foreign profits exceeds the amount necessary to finance basicresearch expenditures, the government would optimally redistribute the surplus via (lump-sum) transfers to the citizens. 
Effect remains unchanged. ${ }^{16}$ Consequently, being able to tax foreign profits decreases the incentive to invest in basic research. This result also holds if one requires domestic firms to be taxed at the same rate as foreign firms, or if all domestic income and foreign profits must be taxed at identical rates.

We note that a polar case could occur, where the maximal tax rate $\bar{\tau}$ on foreign profits is sufficiently high. Then it can be optimal to set $L_{B}=0$, even in circumstances in which the government chooses positive levels of basic research in our basic model.

\subsection{Domestic firms invest abroad}

Our standard framework considers foreign firms entering the domestic market but neglects domestic firms' investments abroad. The model can be extended to allow domestic firms to operate in foreign countries. In accordance with the basic set-up and the discussion in Sect. 3.3, we assume that only a technologically leading domestic firm can be successful in a foreign country. Hence, only domestic type 1 firms will go abroad. Suppose that each domestic type 1 firm will realize expected profits abroad amounting to $\pi_{a} . \pi_{a}$ typically depends both on the size of the foreign markets and on the degree of foreign countries' openness. Profits $\pi_{a}$ are exogenous to the domestic government's decision problem with respect to basic-research expenditures.

Allowing all domestic type 1 firms to go abroad adds the term $s_{1, t} * \pi_{a}$ to the government's objective in the basic model (18) and the constant term $\frac{d s_{1, t}}{d L_{B}} \pi_{a}$ to the first-order condition (21). ${ }^{17}$ Consequently, the optimal amount of basic research unambiguously increases when domestic firms are able to invest abroad. ${ }^{18}$ Also, the qualitative dynamics of the model remain unchanged, but the steady state amount of leading sectors in the home country would increase. Of course, the magnitude of this increase depends crucially on the size of the profits to be gained in foreign countries. Accordingly, if foreign countries become more open to FDI, the home country will react by increasing expenditure on basic research.

\subsection{Private $R \& D$}

The research process in our framework can be interpreted as a simplified way of capturing the role of basic research in facilitating private research, along the lines of Cozzi and Galli (2011a, 2009, 2011b) or Aghion and Howitt (1996). In these papers, basic research creates fundamental ideas taken up by private researchers and developed into marketable products. We have simplified our model by assuming that private, applied R\&D is costless. This should not be taken literally. Rather, it reflects the underlying assumption that the intensity of private $\mathrm{R} \& \mathrm{D}$ in each sector is independent of the amount of basic research.

\footnotetext{
${ }^{16}$ Formally, by including the tax rate $\bar{\tau}$ on foreign profits, $\zeta\left(L_{B}\right)$ as defined by (19) changes to $\zeta\left(L_{B}\right)=$ $s_{1, t}+s_{2, t} \frac{1}{\gamma}+s_{f, t}(1-(1-\bar{\tau}) \alpha(1-\alpha))$. From the first-order condition in Sect. 4 we can infer that the Escape Entry Effect in the basic model is multiplied by the factor $1-\bar{\tau}$ when foreign profits are taxed. Further, we see that the Labor Cost Effect depends on $\zeta\left(L_{B}\right)$. As the latter becomes larger, the Labor Cost Effect increases in magnitude.

${ }^{17}$ Note that whether or not the profits gained in the foreign country are taxed in the domestic country does not affect the extension of the objective function suggested above. This follows from the arguments in Sect. 7.1.

18 Formally, after including the extension, the first-order condition writes $\frac{d c}{d L_{B}}+\frac{d s_{1, t}}{d L_{B}} \pi_{a}=0$, where the first summand reflects the old first-order condition (21). Now since $\frac{d s_{1, t}}{d L_{B}} \pi_{a}$ is positive and independent of $L_{B}$ and $\frac{d^{2} c}{d L_{B}^{2}}<0$, the optimal amount of $L_{B}$ must be larger than in the basic model to satisfy the extended first-order condition.
} 
In Appendix D, we provide a model extension with endogenous applied R\&D. We assume that the firms hire applied researchers to maximize their expected profits. Including endogenous private research, which is complementary to basic research, implies the following. First, the marginal productivity of basic research additionally depends on applied-research intensity. Second, the labor costs increase as private research also draws on the economy's skilled labor supply. In our extended model, we identify the same three effects of basic research as described in the basic model set-up. However, the magnitudes of the effects differ.

\subsection{Foreign firm entry depends on basic research}

So far, the probability that foreign firms will enter the domestic market (our measure of openness $\sigma$ ) has been exogenous. It is conceivable that in some cases multinational firms will locate in countries to benefit from local basic-research activities. ${ }^{19}$ This could be incorporated into the model by letting $\sigma$ be an increasing function of basic research $\sigma\left(L_{B}\right)$. The government's first-order condition then changes to

$$
\left.\frac{d c}{d L_{B}}\right|_{\sigma}+\frac{\partial c}{\partial \sigma} \frac{d \sigma}{d L_{B}}=0
$$

where the first term represents the derivative of the government's objective for a given level of $\sigma$, as in (21) in the basic model. The second term captures the influence of basic research on the probability of foreign firm entry. In this extension, the derivative of $\sigma$ with respect to basic research is positive. If $\sigma$ has a positive effect on domestic consumption, then the last summand is positive, implying that in an interior solution the optimal amount of basic research increases relative to the solution in the basic model set-up. ${ }^{20}$ This is likely to be the case when innovation steps are large. The opposite will be true if openness exerts a negative effect on domestic consumption possibilities, which can occur if innovation steps are small. ${ }^{21}$

Hence, if $\sigma$ positively depends on $L_{B}$, it tends to moderate the relation between openness and $L_{B}$ in the following sense: Consider the formulation $\sigma\left(L_{B}\right)=\bar{\sigma}+\hat{\sigma}\left(L_{B}\right)$, where $\bar{\sigma}$ is an exogenously given level of openness and $\hat{\sigma}\left(L_{B}\right)$ describes the additional attractiveness due to the country's basic-research investments. Without the additional endogenous term in openness $\hat{\sigma}\left(L_{B}\right)$, the relation between optimal basic research and $\bar{\sigma}$ is positive when innovation steps are low, as illustrated in Fig. 2. Our previous discussion suggests that the increase in $L_{B}$ with respect to $\bar{\sigma}$ would be smaller in the scenario with the endogenous part in openness. Intuitively, the main motive for basic research activities is to avoid foreign competition and

\footnotetext{
19 See e.g. Almeida (1996) or Kuemmerle (1999) for empirical evidence.

20 We assume that the maximization problem is still concave, i.e., that the second-order condition for a maximum is satisfied.

21 Taking the derivative of $c$ with respect to $\sigma$ yields

$$
\frac{\partial c}{\partial \sigma}=\psi(w)\left[\left(1-\theta L_{B}\right) s_{1, t-1}+\left(1-\eta \theta L_{B}\right)\left(1-s_{1, t-1}\right)\right]\left[1-\alpha(1-\alpha)-\frac{1}{\gamma}\right]+\frac{d \psi(w)}{d w} \frac{\partial w}{\partial \sigma} \zeta\left(L_{B}\right),
$$

where $\psi(w)=\left(\frac{\alpha^{2} \bar{A}_{t}}{w}\right)^{\frac{\alpha}{1-\alpha}} \cdot \frac{d \psi(w)}{d w}$ is negative and $\frac{\partial w}{\partial \sigma}$ is positive. The reason for the latter is that the foreign firms import leading technology and replace lagging type 2 firms, thus increasing demand for skilled labor in intermediate-goods production. Consequently, the last summand is negative, i.e. there is a labor cost effect due to openness. Concerning the first summand, the term in the second brackets illustrates the main trade-off associated with foreign entry-importing leading technology at the price of intermediate profits that do not accrue to citizens of the country. The first summand is positive for large innovation steps $\gamma$, where the imported leading technology yields higher additional welfare than the profits exported by the foreign firms. For low values of $\gamma$ the first term also becomes negative.
} 
keep profits within the country. When $\sigma$ depends positively on $L_{B}$, basic research is not as effective in pursuing this goal. On the other hand, when innovation steps are large, our results in the basic model indicate that the basic-research levels are lower, the higher the country's openness is in order to import leading technology. With $\sigma$ as an increasing function of $L_{B}$, basic research investment helps to attract foreign firms, so basic research levels will be higher than in the basic set-up.

\subsection{Openness improves technology adoption}

In our basic model set-up, a higher degree of openness increases a country's aggregate productivity only by foreign direct investment of firms with leading technology. This assumption is based on the idea that specific knowledge is necessary to produce world frontier technological products. The latter is brought in by the foreign firm to the domestic sectors lagging behind. However, a country's openness might also induce technological spillovers to domestic firms more directly, e.g. via increased exchange of technological information, turnover of knowledge-bearing employees, or increased trade facilitating reverse engineering.

There are two ways how our model could be adapted to capture direct spillovers from openness to domestic firms. First, let the probability that a foreign firm enters with leading technology be $\phi \sigma$, where $\sigma$ is the degree of openness and $(1-\phi) \in(0,1)$ reflects the strength of spillovers to domestic firms. That is, the probability that a firm whose own innovation efforts were not successful realizes direct spillovers from openness, i.e. adopts a technology from the world frontier without cost and becomes a type-1 leader is $(1-\phi) \sigma$. Adapting the equations of motion for the country's industry structure correspondingly and solving the government's problem reveals that the Labor Cost Effect and the Productivity Effect remain unchanged while the Escape Entry Effect decreases. The latter is due to the fact that only a share $\phi \sigma$ instead of $\sigma$ of the profits go abroad. This decreases the effect of openness on the incentives to invest in basic research.

A second way to extend our model would be to make the productivity of basic research dependent on the degree of openness: $\theta(\sigma)$. Then a higher degree of openness increases the knowledge spillovers realized from abroad which allow a better use of the basic research inputs to create world leading technology. In this case, an increase in $\sigma$ would cause higher values of $\theta$ thereby making basic research investments more attractive.

\section{Empirical support}

In this section, we provide some empirical support for our main theoretical prediction that the effect of openness on basic research depends on the size of the innovation steps. Limited data availability on basic research expenditures poses a considerable challenge for an empirical investigation. Hence, our analysis in this section represents a first pass in which we focus on the type of regressions that appear to be most suitable to address the hypothesis. A more complete empirical investigation and the examination of alternative specifications is left for future research when more data will be available.

8.1 Empirical specification and data description

We consider the following empirical specification

$$
\text { Basic Research }_{i t}=\beta_{0}+\beta_{1} \gamma_{i t}+\beta_{2} \sigma_{i t}+\beta_{3} \gamma_{i t} * \sigma_{i t}+\delta \mathbf{X}_{\mathrm{it}}+\tau_{t}+\alpha_{i}+\varepsilon_{i t},
$$


with basic research expenditures on the left-hand side and innovation steps $\gamma_{i t}$, openness $\sigma_{i t}$ and the interaction between these two variables on the right-hand side of the equation. The matrix $\mathbf{X}_{\mathbf{i t}}$ comprises additional control variables, which we describe below. To preclude spurious correlations simply because variables are trending, we control for exponential trends in all our estimations. Moreover, we include a full set of time dummies to rule out that our results are driven by period-specific effects. The respective terms are included in $\tau_{t}$ in (29). ${ }^{22}$ The parameter $\alpha_{i}$ captures unobserved time-invariant country-specific characteristics and $\varepsilon_{i t}$ represents the error term.

We use five year averages of unbalanced panel data from 1981 to 2005 including most OECD countries. ${ }^{23}$ The only source of data on basic research expenditures is the OECD's Main Science and Technology Indicators Database (OECD 2010) where we obtain basic research expenditures as a percentage of GDP. We use the economic globalization index available at KOF (Dreher 2006) as our measure of the countries' openness which incorporates actual economic flows such as foreign direct investment and trade, as well as economic restrictions like tariffs and capital account restrictions. In this way, the economic globalization index provides a comprehensive measure of openness. ${ }^{24}$ In the appendix, we show that we obtain similar results when instead using data on foreign direct investment provided by the World Bank to reflect the countries' openness.

Data on the countries' per capita growth rates of GDP, provided by the World Bank's World development indicators (WDI) (World Bank 2010), are taken as a proxy of the innovation steps $\gamma .{ }^{25}$ In all of the following estimations we include the share of the population with completed tertiary education available from Barro and Lee's data set on educational attainment (Barro and Lee 2010) and the countries' distance to the technological frontier which is calculated as the relative difference of the country's GDP per capita to U.S.-GDP per capita. Those data are taken from WDI.

In some regressions we include further variables taken from WDI to control for potential differences in the productivity of basic research. These are: strength of legal rights index (weak=0 to strong=10), the average costs of business start-up procedures (perc. of GDP/capita), income and profit taxes (perc. of total taxes), taxes on goods and services (perc. of value added in industry and services), government consumption expenditures (perc. of

22 That is, $\tau_{t}=\lambda_{0} t+\lambda_{1} t_{1}+\lambda_{2} t_{2}+\lambda_{3} t_{3}+\cdots$, where $t_{1}, t_{2}, \ldots$ represent the period dummies for periods $t=1$ (1981-1985), $t=2$ (1986-1990), and so on. However, our results do not change substantially when controlling only for time dummies or trends.

23 Averages are taken for the time periods 1981-1985, 1986-1990, and so forth. If not all 5 observations within the respective 5-year period are available, we use the average of the available observations and interpret it as the 5 year average (i.e., we impute the average value of the available observations for the missing values within the respective 5-year period). The following OECD-countries cannot be included in the analysis either because data on the dependent or on one of the independent variables are missing. In the regressions without the time-invariant controls: Belgium, Canada, Chile, Finland, Greece, Hungary, Luxembourg, Turkey, United Kingdom. When the time-invariant controls are included in the regression model, the countries Denmark, Iceland, Ireland, Israel, and New Zealand additionally drop out of the sample.

24 More precisely, data on actual flows includes Trade (perc. of GDP), Foreign Direct Investment (perc. of GDP), Portfolio Investment (perc. of GDP), and Income Payments to Foreign Nationals (perc. of GDP). Data on economic restrictions contain Hidden Import Barriers, Mean Tariff Rate, Taxes on International Trade, and Capital Account Restrictions. A precise description of the data and its sources can be found at http:// globalization.kof.ethz.ch/.

25 In principle, it would be possible to use the growth rate of GDP per capita of the U.S. as a proxy of the growth rate of the world's technological frontier. By using country-specific growth rates, we allow for the innovation steps to differ across countries. This may reflect infrastructure or institutional differences across countries that may impact technology adoption and thus cause that innovation steps differ. Including country specific growth rates provides a further source of variation for the empirical analysis. 
GDP), natural resource rents (perc. of GDP), domestic credit provided by banking sector (perc. of GDP), and bank non-performing loans (perc. of total gross loans). Data on these controls are even scarcer than on our dependent variables and main regressors. Further, the within-country variation of the data on these variables is substantially smaller than the between-country variation. For these reasons, we will only employ time-invariant country averages of these variables.

Except for the share of the population with tertiary education and the measure on the strength of legal rights, we use all variables (also the dependent variable, i.e. basic research expenditures) in logarithmic scale. Accordingly, the corresponding coefficients can be interpreted as elasticities.

\subsection{Empirical procedure and estimation results}

Our main theoretical result that openness has a positive effect on basic research expenditures when innovation steps are low and a negative effect when innovation steps are high suggests that $\beta_{2}>0$ and $\beta_{3}<0$.

As unobserved country-specific heterogeneity may be correlated with the regressors, we start by estimating a fixed effects regression model. The first column in Table 4 shows the results without the interaction term between growth and openness while the second column illustrates the results when the interaction term is included. The results indicate that without the interaction term openness has no significant effect on basic research expenditures. However, we observe in the second column of Table 4 that the coefficient of the interaction term possesses the expected negative sign and is highly significant. Moreover, the coefficient of openness $\beta_{2}$ also shows the expected positive sign and an $\mathrm{F}$ test reveals that $\beta_{2}$ and $\beta_{3}$ are jointly significant.

We obtain similar results when applying a random effects regression model or a pooled regression as indicated in columns (3) and (4). However, in the pooled regression the significance level of the coefficient of the interaction term decreases slightly. ${ }^{26}$

A Hausman-test cannot reject the hypothesis that the estimated values of the coefficients in the fixed effects model differ from those in the random effects model. ${ }^{27}$ This allows us to use the more efficient random effects model and to include additional time-invariant controls. As mentioned in the data description section, these variables mainly control for the productivity of basic research as reflected in the parameters $\theta$ and $\eta$ in the theoretical model. ${ }^{28}$

As indicated in columns (5)-(7), including these controls into our econometric model does not change our main results. Again, openness shows no significant influence on basic research expenditures when the interaction term between openness and growth is not taken into account (col. (5)). With its inclusion, the interaction term is highly significant in both the random effects model (col. (6)) and the pooled regression (col. (7)). Note that in the random effects regression model (col. (6)) the $p$ value of the interaction term is only slightly higher than 0.01 at 0.0123 . Again, $\beta_{2}$ and $\beta_{3}$ are jointly significant in the random effects as well as in the pooled regression model.

\footnotetext{
26 The $p$ value of the interaction term in the pooled regression is 0.028 versus 0.001 in the random effects estimation and 0.0037 in the fixed effects model.

27 The test of $\mathrm{H}_{0}$ : "The difference in coefficients of (2) and (3) is not systematic" yields a $p$ value of 0.999. Hence $\mathrm{H}_{0}$ cannot be rejected.

28 Due to the small number of within-country observations on these variables, we are not able to add these controls to the fixed effects estimation. Otherwise, our already small sample would have been reduced even further, thereby substantially decreasing the degrees of freedom of our estimation.
} 
Table 4 Main results

Log basic research expenditures/GDP

\begin{tabular}{|c|c|c|c|c|c|c|c|}
\hline & $\begin{array}{l}(1) \\
\text { FE }\end{array}$ & $\begin{array}{l}(2) \\
\text { FE }\end{array}$ & $\begin{array}{l}(3) \\
\mathrm{RE}\end{array}$ & $\begin{array}{l}(4) \\
\text { Pooled }\end{array}$ & $\begin{array}{l}(5) \\
\mathrm{RE}\end{array}$ & $\begin{array}{l}(6) \\
\mathrm{RE}\end{array}$ & $\begin{array}{l}(7) \\
\text { Pooled }\end{array}$ \\
\hline Log growth & $\begin{array}{l}0.049 \\
(0.051)\end{array}$ & $\begin{array}{l}2.037 * * * \\
(0.635)\end{array}$ & $\begin{array}{l}2.176 * * * \\
(0.672)\end{array}$ & $\begin{array}{l}3.206^{* *} \\
(1.354)\end{array}$ & $\begin{array}{l}-0.009 \\
(0.045)\end{array}$ & $\begin{array}{l}1.805 * * \\
(0.738)\end{array}$ & $\begin{array}{l}2.678 * * \\
(1.049)\end{array}$ \\
\hline Log openness & $\begin{array}{l}0.156 \\
(0.686)\end{array}$ & $\begin{array}{l}0.623 \\
(0.621)\end{array}$ & $\begin{array}{l}0.577 \\
(0.575)\end{array}$ & $\begin{array}{l}0.398 \\
(0.628)\end{array}$ & $\begin{array}{l}0.226 \\
(0.562)\end{array}$ & $\begin{array}{l}0.777 \\
(0.529)\end{array}$ & $\begin{array}{l}1.160 * * \\
(0.522)\end{array}$ \\
\hline $\begin{array}{l}\text { Log openness } * \\
\log \text { growth }\end{array}$ & & $\begin{array}{l}-0.469 * * * \\
(0.146)\end{array}$ & $\begin{array}{l}-0.503 * * * \\
(0.154)\end{array}$ & $\begin{array}{l}-0.749 * * \\
(0.320)\end{array}$ & & $\begin{array}{l}-0.428 * * \\
(0.171)\end{array}$ & $\begin{array}{l}-0.629 * * \\
(0.240)\end{array}$ \\
\hline $\begin{array}{l}\text { Log distance } \\
\text { to frontier }\end{array}$ & $\begin{array}{l}0.328 \\
(0.259)\end{array}$ & $\begin{array}{l}0.423 * \\
(0.233)\end{array}$ & $\begin{array}{l}0.474 * * * \\
(0.125)\end{array}$ & $\begin{array}{l}0.461 * * * \\
(0.149)\end{array}$ & $\begin{array}{l}0.314 * \\
(0.181)\end{array}$ & $\begin{array}{l}0.295 \\
(0.184)\end{array}$ & $\begin{array}{l}0.584 * * * \\
(0.171)\end{array}$ \\
\hline $\begin{array}{l}\text { Share of population } \\
\text { w. tertiary education }\end{array}$ & $\begin{array}{l}0.004 \\
(0.012)\end{array}$ & $\begin{array}{l}0.011 \\
(0.011)\end{array}$ & $\begin{array}{l}0.018 * * \\
(0.009)\end{array}$ & $\begin{array}{l}0.024 * \\
(0.013)\end{array}$ & $\begin{array}{l}0.005 \\
(0.011)\end{array}$ & $\begin{array}{l}0.007 \\
(0.013)\end{array}$ & $\begin{array}{l}0.056 * * \\
(0.024)\end{array}$ \\
\hline Time-invar. controls & No & No & No & No & Yes & Yes & Yes \\
\hline$R^{2}$ & 0.514 & 0.566 & 0.410 & 0.443 & 0.690 & 0.700 & 0.777 \\
\hline$N$ & 81 & 81 & 81 & 81 & 69 & 69 & 69 \\
\hline
\end{tabular}

Notes: In all regressions we controlled for time trends and periodic effects via time dummies. Controlling only for either of the two do not affect the results substantially. Standard error estimates are cluster-robust (cluster is country) and reported in parentheses

*** Significant at the $1 \%$ level

** Significant at the $5 \%$ level

* Significant at the $10 \%$ level

There might be concern regarding the potential endogeneity of the regressors due to omitted variables or reverse causality. Given that there is typically a substantial time lag between basic research expenditures and their effect via knowledge generation on GDP growth, the distance to the technological frontier, and possibly openness, it is unlikely that reverse causality matters significantly in our specification.

Nevertheless, we estimate the random effects model using two-stage-least squares with one period lags as instruments for the variables growth, openness and distance to frontier. The estimation results are reported in Appendix E. At the first stage, the one-period lags turn out to satisfy instrument relevance, indicated by $\mathrm{F}$ tests of joint significance of the instruments in the reduced form regressions and a rank test of the reduced form equations. The second stage estimates indicate that the signs of the coefficients remain the same as the ones in the regressions reported in Table 4. In particular, the coefficient of the interaction term between openness and growth is negative. However, the corresponding $p$ value is only about 0.2 . The $p$ values of most of the other coefficients are of similar size. This reflects the decrease of the degrees of freedom (using lags as instruments reduces the number of observations from 69 to only 48) and the lower efficiency of the IV-estimator. Although these results are suggestive, the endogeneity of regressors should be readdressed when a larger data set will be available. ${ }^{29}$

In summary, we provided some empirical support for the importance of our theoretical results. As mentioned at the beginning, the empirical results have to be interpreted with

29 Future reassessments will be possible as many of the large organizations such as the World Bank and the OECD are collecting data on a regular basis and have substantially increased the scope of variables they are collecting. 
caution. ${ }^{30}$ As more and more data become available in the future, the scope for empirical analyses will increase. Our results lend confidence that our theoretical predictions will find empirical support in later studies with substantially larger data sets.

\section{Conclusion}

We develop a model of growth that incorporates basic research and the entry of foreign hightech firms, while the level of basic research is determined by a government maximizing the consumption of the current generation. On that basis, we derive the steady states of the economy and study how changes in the degree of openness affect the incentives to invest in basic research. Our main insight that a higher degree of openness tends to justify higher investment in basic research may be important for policy discussions in industrialized countries.

Acknowledgments We would like to thank Christian Almer, Clive Bell, Guido Cozzi, Silvia Galli, Volker Hahn, Hans Haller, Martin Hellwig, Ralph Winkler, participants of the Conference on the Economics of Technology Policy at Monte Verita, and seminar participants in Berlin, Zurich, and Heidelberg for valuable comments. We greatly appreciate the comments and suggestions of three anonymous referees. This work was supported by ETH Research Grant ETH-05 08-1.

\section{A Proofs}

\section{A.1 Proof of Lemma 1}

Using (15) to determine the derivative $\frac{d w\left(L_{B}\right)}{d L_{B}}$ we obtain

$$
\frac{d w\left(L_{B}\right)}{d L_{B}}=(1-\alpha) \alpha^{2} \bar{A}_{t}^{\alpha}\left[\frac{\chi\left(L_{B}\right)}{\bar{L}-L_{B}}\right]^{-\alpha} \frac{\chi^{\prime}\left(\bar{L}-L_{B}\right)+\chi\left(L_{B}\right)}{\left(\bar{L}-L_{B}\right)^{2}} .
$$

Since $\chi\left(L_{B}\right)=\chi^{\prime} L_{B}+\bar{\chi}$, the numerator of the last fraction can be written as $\chi^{\prime} \bar{L}+\bar{\chi}=$ $\chi(\bar{L})$. From the definition of $\chi\left(L_{B}\right)$ according to Eq. (14) we know that $\chi\left(L_{B}\right)$ is positive for all values of $L_{B}$. As a consequence, $\frac{d w\left(L_{B}\right)}{d L_{B}}>0$.

\section{A.2 Proof of Proposition 1}

By inserting (15) in (18), the government's objective function reads

$$
c=\zeta\left(L_{B}\right)\left(\frac{\bar{A}_{t}\left(\bar{L}-L_{B}\right)}{\chi\left(L_{B}\right)}\right)^{\alpha} .
$$

It yields the following first-order condition with respect to the choice of $L_{B}$ :

$$
\frac{\alpha \chi(\bar{L})}{\chi\left(L_{B}\right)\left(\bar{L}-L_{B}\right)} \zeta\left(L_{B}\right)=\zeta^{\prime}
$$

By expansion, this condition can be transformed to

$$
\bar{L}(\alpha \hat{\zeta}-\hat{\chi})+\alpha \hat{\zeta} \hat{\chi}+L_{B}[(1+\alpha) \hat{\chi}-(1-\alpha) \bar{L}]+L_{B}^{2}=0 .
$$

\footnotetext{
30 For example, the results could suffer from selection bias if some countries have particular reasons (correlated with our regressors) for not providing data on basic research expenditures. Moreover, it will be useful to employ more refined measures of innovation steps.
} 
The solution to this quadratic equation is

$$
L_{B}=\frac{1-\alpha}{2} \bar{L}-\frac{1+\alpha}{2} \hat{\chi} \pm \sqrt{\left(\frac{1-\alpha}{2} \bar{L}-\frac{1+\alpha}{2} \hat{\chi}\right)^{2}-(\alpha \hat{\zeta}-\hat{\chi}) \bar{L}-\alpha \hat{\zeta} \hat{\chi}}
$$

In order to determine which of the two solutions maximizes period $t$ consumption, consider the government's objective function as given in (18):

$$
\left(\frac{\alpha^{2} \bar{A}_{t}}{w}\right)^{\frac{\alpha}{1-\alpha}}\left[s_{1, t}+s_{2, t} \frac{1}{\gamma}+s_{f, t}(1-\alpha(1-\alpha))\right] .
$$

From Lemma 1 we know that the wage strictly increases with $L_{B}$. Taking a close look at $w\left(L_{B}\right)$ given in Eq. (15), we see that for $L_{B} \rightarrow \bar{L}$, the wage becomes infinite. As the second factor in (18), $\zeta\left(L_{B}\right)$, is bound from above for $L_{B} \rightarrow \bar{L}$, consumption converges to 0 if the entire skilled labor force is employed in the basic-research sector. Moreover, we see that $c$ cannot become negative, so when $L_{B} \rightarrow \bar{L}$, it converges to 0 from above. As a next step, we show that the objective function is concave in $L_{B}$, which implies that the second derivative of (30) with respect to $L_{B}$ should be negative:

$$
\begin{gathered}
\bar{A}_{t}^{\alpha}\left[-2 \alpha \zeta^{\prime}\left(\frac{\bar{L}-L_{B}}{\chi\left(L_{B}\right)}\right)^{\alpha-1} \frac{\chi\left(L_{B}\right)+\chi^{\prime}\left(\bar{L}-L_{B}\right)}{\chi\left(L_{B}\right)^{2}}\right. \\
\quad-\alpha(1-\alpha) \zeta\left(L_{B}\right)\left(\frac{\bar{L}-L_{B}}{\chi\left(L_{B}\right)}\right)^{\alpha-2}\left(\frac{\chi\left(L_{B}\right)+\chi^{\prime}\left(\bar{L}-L_{B}\right)}{\chi\left(L_{B}\right)^{2}}\right)^{2} \\
\left.+2 \alpha \zeta\left(L_{B}\right)\left(\frac{\bar{L}-L_{B}}{\chi\left(L_{B}\right)}\right)^{\alpha-1} \frac{\chi^{\prime}\left(\chi\left(L_{B}\right)+\chi^{\prime}\left(\bar{L}-L_{B}\right)\right)}{\chi\left(L_{B}\right)^{3}}\right]<0 .
\end{gathered}
$$

The middle term is negative, so we can neglect it. The remaining part can be reduced to

$$
-\zeta^{\prime} \bar{\chi}+\chi^{\prime} \bar{\zeta}<0
$$

which equals

$$
\begin{aligned}
& -\left[s_{1, t-1} \theta(1-\eta)+\eta \theta\right]\left((1-\sigma)\left(1-\frac{1}{\gamma}\right)+\sigma \alpha(1-\alpha)\right)\left(\sigma+(1-\sigma) \frac{1}{\gamma}\right) \\
& +\left[s_{1, t-1} \theta(1-\eta)+\eta \theta\right](1-\sigma)\left(1-\frac{1}{\gamma}\right)\left((1-\sigma) \frac{1}{\gamma}+\sigma(1-\alpha(1-\alpha))\right)<0 .
\end{aligned}
$$

The inequality can be further reduced to the form

$$
-\left[s_{1, t-1} \theta(1-\eta)+\eta \theta\right] \sigma \alpha(1-\alpha)<0,
$$

which obviously holds. Hence, we now know that (30) either falls monotonically in the interval $L_{B} \in[0, \bar{L})$ or it features a single extremum, which must be a maximum. To show that

$$
L_{B}^{+}=\frac{1-\alpha}{2} \bar{L}-\frac{1+\alpha}{2} \hat{\chi}+\sqrt{\left(\frac{1-\alpha}{2} \bar{L}-\frac{1+\alpha}{2} \hat{\chi}\right)^{2}-(\alpha \hat{\zeta}-\hat{\chi}) \bar{L}-\alpha \hat{\zeta} \hat{\chi}},
$$

the larger of the two solutions given in (31) always constitutes the possible maximum, it is sufficient to show that $L_{B}^{+}<\bar{L}$ holds. A number of algebraic manipulations transform this condition into

$$
(\bar{L}+\hat{\chi})(\bar{L}+\hat{\zeta})>0
$$


The fact that condition (32) is satisfied is straightforward, as $\hat{\chi}>0$ and $\hat{\zeta}>0$ due to $\bar{\chi}, \bar{\zeta}, \chi^{\prime}, \zeta^{\prime}>0$.

Finally, $L_{B}^{+}$constitutes a maximum in the relevant interval $L_{B} \in\left[0, \frac{1}{\theta}\right]$, given that $0 \leq$ $L_{B}^{+} \leq 1 / \theta$ and $L_{B}^{+} \in \mathbb{R}$. The latter condition guarantees that the expression under the square root of $L_{B}^{+}$is positive.

If $L_{B}^{+}>1 / \theta$, it is clear that the objective function is increasing with $L_{B}$ over the entire relevant range $L_{B} \in\left[0, \frac{1}{\theta}\right]$. Hence, in this case $L_{B}=\frac{1}{\theta}$ is the solution to the maximization problem.

\section{A.3 Steady-state analysis}

Using the unique solution with respect to basic-research investment as given in Proposition 1 , we obtain the steady-state amount of domestic high technology sectors, $s_{1}^{s}$, by solving

$$
s_{1}=L_{B}\left(s_{1}\right) \underbrace{\left[s_{1} \theta(1-\eta)+\eta \theta\right]}_{\psi\left(s_{1}\right)} .
$$

First we rearrange (33) according to

$$
\theta L_{B}\left(s_{1}\right)=\frac{\theta s_{1}}{s_{1} \theta(1-\eta)+\eta \theta}
$$

in order to check that for all interior solutions $0<s_{1}^{s}<1$ the condition $0<L_{B}<\frac{1}{\theta}$ must hold. It is straightforward that this is the case, as the right-hand side increases with $s_{1}$ and reaches one when $s_{1}=1$ and zero when $s_{1}=0$. This implies that we can focus on $L_{B}=L_{B}^{+}$ as given in Proposition 1 to determine the interior solutions.

We redefine $\zeta^{\prime}$ as $\psi\left(s_{1}\right) \tilde{\zeta}$, where $\tilde{\zeta}=(1-\sigma)\left(1-\frac{1}{\gamma}\right)+\sigma \alpha(1-\alpha)$, and similarly we can rewrite $\chi^{\prime}$ as $\psi\left(s_{1}\right) \tilde{\chi}$, where $\tilde{\chi}=(1-\sigma)\left(1-\frac{1}{\gamma}\right)$. By inserting $L_{B}^{+}$into (33), the equation transforms to

$$
\begin{array}{r}
s_{1}^{2}[(1-\alpha) \bar{L} \theta(1-\eta)-1]+s_{1}\left(\bar{L}\left[\theta(1-\eta)\left(\frac{\bar{\chi}}{\tilde{\chi}}-\alpha \frac{\bar{\zeta}}{\tilde{\zeta}}\right)+(1-\alpha) \eta \theta\right]-(1+\alpha) \frac{\bar{\chi}}{\tilde{\chi}}\right) \\
+\eta \theta \bar{L}\left(\frac{\bar{\chi}}{\tilde{\chi}}-\alpha \frac{\bar{\zeta}}{\tilde{\zeta}}\right)-\alpha \frac{\bar{\chi}}{\tilde{\chi}} \frac{\bar{\zeta}}{\tilde{\zeta}}=0 .
\end{array}
$$

As this is a quadratic equation in $s_{1}$, there can be no more than two steady states where $L_{B}=L_{B}^{+}$.

With respect to steady states at the corners $s_{1}=0$ and $s_{1}=1$, we can state the following: If $L_{B}^{+}(0) \leq 0$ there exists a steady state at $s_{1}=0$. From Proposition 1 we know that $L_{B}=0$ if $L_{B}^{+}\left(s_{1, t-1}\right) \leq 0$. Thus, it is clear that condition (33) is satisfied under these circumstances. Similarly, if $L_{B}^{+}(1) \geq \frac{1}{\theta}$ there exists a steady state at $s_{1}=1$. Again, from Proposition 1 we know that $L_{B}=\frac{1}{\theta}$ if $L_{B}^{+}\left(s_{1, t-1}\right) \geq \frac{1}{\theta}$. That (33) holds for $L_{B}=\frac{1}{\theta}$ and $s_{1}=1$ is straightforward.

With the above considerations we can now proceed to a complete steady-state analysis:

1. If $L_{B}^{+}(0)>0$ and $L_{B}^{+}(1)<\frac{1}{\theta}$, then $L_{B}\left(s_{1}\right) \psi\left(s_{1}\right)$ crosses the bisectoral line once only and from above at $0<s_{1}<1$. Thus, there exists a unique and stable steady state with $0<s_{1}^{s}<1$.

2. If $L_{B}^{+}(0)>0$ and $L_{B}^{+}(1)=\frac{1}{\theta}$, then $L_{B}\left(s_{1}\right) \psi\left(s_{1}\right)$ either crosses the bisectrix once only and from above at $s_{1}=1$ or it crosses the bisectrix twice, first from above at $0<s_{1}<1$, 
and second from below at $s_{1}=1$. In the first case, the corner solution $s_{1}^{s}=1$ is the unique and stable steady state. In the second case, only the steady state with $0<s_{1}^{s}<1$ is stable.

3. If $L_{B}^{+}(0)>0$ and $L_{B}^{+}(1)>\frac{1}{\theta}$, then $L_{B}\left(s_{1}\right) \psi\left(s_{1}\right)$ either crosses the bisectrix once only and from above at $s_{1}=1$ or it crosses the bisectrix three times, first from above at $0<s_{1}^{a}<1$, second from below at $0<s_{1}^{b}<1$, where $s_{1}^{a}<s_{1}^{b}$, and third from above at $s_{1}=1$. In the first case, the corner solution $s_{1}^{s}=1$ is the unique and stable steady state. In the second case, only $s_{1}^{a}$ of the two interior steady states is stable. A second stable steady state is given at the corner $s_{1}^{s}=1$.

4. If $L_{B}^{+}(0)=0$ and $L_{B}^{+}(1)<\frac{1}{\theta}$, then $L_{B}\left(s_{1}\right) \psi\left(s_{1}\right)$ either crosses the bisectrix once only and from above at $s_{1}=0$ or it crosses the bisectoral line twice, first from below at $s_{1}=0$ and then from above at $0<s_{1}<1$. In the first case, the corner solution $s_{1}^{s}=0$ is the unique and stable steady state. In the second case, only the steady state with $0<s_{1}^{s}<1$ is stable.

5. If $L_{B}^{+}(0)=0$ and $L_{B}^{+}(1)=\frac{1}{\theta}, L_{B}\left(s_{1}\right) \psi\left(s_{1}\right)$ crosses the bisectrix twice, first at $s_{1}=0$ then at $s_{1}=1$. If $L_{B}\left(s_{1}\right) \psi\left(s_{1}\right)>s_{1}\left(<s_{1}\right)$ at $s_{1} \in(0,1)$, then it crosses the bisectrix from below (above) at $s_{1}=0$ and from above (below) at $s_{1}=1$. Hence, the unique and stable steady state is given by the corner solution $s_{1}^{s}=1\left(s_{1}^{s}=0\right)$.

6. If $L_{B}^{+}(0)=0$ and $L_{B}^{+}(1)>\frac{1}{\theta}$, then $L_{B}\left(s_{1}\right) \psi\left(s_{1}\right)$ crosses the bisectoral line either twice, first at $s_{1}=0$ from below then at $s_{1}=1$ from above, or it crosses the bisectrix three times, first from above at $s_{1}=0$, second from below at $0<s_{1}<1$, and third from above at $s_{1}=1$. In the first case, only the corner steady state given by $s_{1}^{s}=1$ is stable. In the second case, the interior steady state is not stable, while both corner solutions $s_{1}^{s}=0$ and $s_{1}^{s}=1$ are stable steady states.

7. If $L_{B}^{+}(0)<0$ and $L_{B}^{+}(1)<\frac{1}{\theta}$, then $L_{B}\left(s_{1}\right) \psi\left(s_{1}\right)$ either crosses the bisectrix once only and from above at $s_{1}=0$ or it crosses the bisectoral line three times, first from above at $s_{1}=0$, second from below at $0<s_{1}^{a}<1$, and third from above at $0<s_{1}^{b}<1$, whereas $s_{1}^{a}<s_{1}^{b}$. In the first case, the corner solution $s_{1}^{s}=0$ is the unique and stable steady state. In the second case, only $s_{1}^{b}$ of the two interior steady states is stable. A second stable steady state is given at the corner $s_{1}^{s}=0$.

8. If $L_{B}^{+}(0)<0$ and $L_{B}^{+}(1)=\frac{1}{\theta}$, then $L_{B}\left(s_{1}\right) \psi\left(s_{1}\right)$ either crosses the bisectrix twice, first at $s_{1}=0$ from above then at $s_{1}=1$ from below, or it crosses the bisectrix three times, first from above at $s_{1}=0$, second from below at $0<s_{1}<1$, and third from above at $s_{1}=1$. In the first case, only the corner steady state given by $s_{1}^{s}=0$ is stable. In the second case, the interior steady state is not stable, while both corner solutions $s_{1}^{s}=0$ and $s_{1}^{s}=1$ are stable steady states.

9. If $L_{B}^{+}(0)<0$ and $L_{B}^{+}(1)>\frac{1}{\theta}$, then $L_{B}\left(s_{1}\right) \psi\left(s_{1}\right)$ crosses the bisectrix three times, first at $s_{1}=0$ from above, second at $0<s_{1}<1$ from below, and third at $s_{1}=1$ from above. Thus, the interior steady state is not stable, while both corner solutions $s_{1}^{s}=0$ and $s_{1}^{s}=1$ are stable steady states.

\section{B Concept of openness}

The concept of openness introduced in our model can be interpreted as follows:

We assume that firms headquartered in a foreign country and owned by foreigners incur costs from introducing a leading technology into the domestic market and operating in a 
foreign country. ${ }^{31}$ Those costs are heterogeneous and depend on the country's degree of openness. ${ }^{32}$ The higher the country's openness, the more likely it is that an innovating foreign firm will find it profitable to introduce the new technology into the domestic market. In this way, we specify openness as the probability $\sigma$ that an innovating foreign firm will benefit from entering the domestic market.

An alternative view on openness is the following: The outside world that forms the technological frontier is divided into two parts. Firms in the first part incur small costs by entering the domestic country and operating in it. The probability that innovations in this part will push the technological frontier of a particular industry to the next level is given by $\sigma(0<\sigma<1)$. Firms in the second part of the outside world have high entry costs and are deterred from entering the domestic market under any circumstances. The probability of the rise in the technological frontier in a specific industry being caused by innovations in this part of the world is $1-\sigma$.

Our model is compatible with both perspectives on openness. The consequences of either view of openness for the domestic industries are as stated in Sect. 3.3:

- If the domestic firm lags behind the technological frontier, a foreign firm will enter with probability $\sigma$ and capture the entire market in this sector.

- If the domestic firm produces at the technological frontier, no foreign entry will occur in the respective sector.

We note that due to the assumption that operating in the domestic market is costly for a foreign firm, Bertrand competition implies negative profits for the foreign firm if it possesses the same technological level as the domestic firm (which would realize zero profits). Hence, the foreign firm will only enter or stay in the market if its technological level is higher than that of the domestic firm.

\section{Foundation of the model with patent races}

In this section, we provide another interpretation of the model's micro-foundation using patent races.

In each sector, there is a finite number of domestic firms that can engage in innovation/patent races at the beginning of each period. There are two types of $R \& D$ projects that the firms may conduct:

(1) high-risk research aiming at technological level $\bar{A}_{t}$

(2) low-risk research aiming either at technological level $\bar{A}_{t-1}$ (e.g., adopting an existing intermediate technology from the previous world technology frontier) or at inventing around an existing patent of an intermediate good producer at technological level $\bar{A}_{t-1}$.

Establishing a research project of type (2) incurs a small fixed $\operatorname{cost} \varepsilon>0$, caused e.g. by the necessity to first learn about the existing intermediate goods at this technology level. For simplicity, we assume that the risky research project will not incur costs. In both types of

\footnotetext{
31 This concept is reminiscent of treating entry costs in the Melitz-type trade models (e.g. Melitz 2003).

32 For example, if the technology is developed abroad, the introduction of the new technology may be hampered by the legal and institutional framework in the domestic country. Further, the introduction of a new technology in a different country may necessitate the build-up or restructuring of production capacities, the employment of experts from the foreign country, and the like. The amount of costs incurred by these activities is likely to differ depending on the technology and the structure of the innovating foreign firm. Further, it is also very likely that these costs will be lower in countries that are very open to foreign trade and FDI.
} 
$\mathrm{R} \& \mathrm{D}$, the first firm to succeed obtains a patent valid for two periods (which is 'de facto' equivalent to a patent of longer validity).

With respect to research project (1), we assume that each firm possesses the same probability of innovation success, depending on the level of basic research. Also, each firm that participates in the race possesses equal probability of being the first to be successful. Since there are no fixed costs for participating in the patent race, all firms will participate in the risky innovation project (1). ${ }^{33}$ The probability that one firm will succeed in creating an innovation at the new technological frontier is $\rho_{1}\left(L_{B}\right)$ if the respective sector has been in state 1 in the previous period and $\rho_{2}\left(L_{B}\right)$ if the sector was in state 2 or $\mathrm{f}$ before. ${ }^{34}$

For the low-risk project (2), the probability that a firm will be successful is one, and the fastest firm obtains the patent. In each period, the following sequence of events occur:

1. Government chooses basic research

2. Domestic firms engage in risky research projects

3. Technological frontier increases to $\bar{A}_{t}=\gamma^{\frac{1-\alpha}{\alpha}} \bar{A}_{t-1}$

4. If no domestic firm was successful in the risky research project, domestic firms may decide to enter the patent race with low-risk research at a small cost $\varepsilon$

5. Foreign intermediate firms decide whether to enter (or keep on operating in) the domestic market

6. Production of consumption good

Again, in the subgame-perfect equilibrium, the foreign firm will only enter (or keep operating) if it is able to offer an intermediate good at a higher technological level. ${ }^{35}$ Concerning the patent race with low-risk research, domestic firms will only participate if in period $t$ no domestic patent for an intermediate with technological level $A_{t-1}$ exists. Note that if a patent held by a foreign firm exists, it will be profitable to invent around it in anticipation of the foreign firm leaving the market if competition at the same technological level ensues. ${ }^{36}$ Of course, this is just one interpretation of our set-up. One can easily find others that add further realistic features, such as simultaneous patent races with respect to high- and low-risk research.

\section{Extended model with private $R \& D$}

We outline an extended model that includes private R\&D. ${ }^{37}$ Suppose that instead of (6) and (7) the probability of innovation success of a type $j$ firm, $j=1,2$, is

$$
\rho_{j}\left(L_{B}, L_{A, j}\right)=\min \left\{\sqrt{\theta_{j} L_{B} L_{A, j}}, 1\right\},
$$

\footnotetext{
33 Note that we could also assume that the risky project is costly for the firms. Then, however, there exists a positive level of $L_{B}$ for which $\rho_{1}\left(L_{B}\right)$ and $\rho_{2}\left(L_{B}\right)$ are zero because no firm will participate in the innovation race due to prospects of negative profits from participating.

34 This assumption reflects the familiarity of the domestic firms with previous frontier technology.

35 This is due to the small operating costs in the domestic market.

36 With the current specification of the game, it may occur for $\sigma$ very close to one that no firm will find it profitable to engage in the second patent race because no firm succeeded in the first one, even if no domestic patent at the $\bar{A}_{t-1}$ level exists. This can be avoided by assuming that the incumbent (e.g. the type 2 firm that operated in the market in the previous period or the one that has been outcompeted by the foreign firm) can participate in the race without costs, while the 'outsiders' incur participation costs.

37 See Gersbach et al. (2010) for a detailed analysis of how openness affects the interplay between basic and applied research in a static model. Here we provide a short sketch of such an extension.
} 
where $L_{A, j}$ denotes private or applied R\&D of a type $j$ firm. The specification in Eq. (34) exhibits complementarities between basic and applied research. Let $\theta_{1}=\hat{\theta}$ and $\theta_{2}=\eta \hat{\theta}$. For simplicity, we assume that in all sectors, $s_{1, t-1}$ and $s_{2, t-1}$, applied research is conducted by type 1 or type 2 incumbents, respectively. In the sectors occupied by a foreign firm, a type 2 firm employs applied researchers in the hope of leapfrogging to the technological frontier. ${ }^{38}$ Given the technological level $A(i)$ of the intermediate product $i$, a monopolist can earn profits as given by (5). Consequently, the type $j$ firm will choose the optimal number of applied researchers in its private $\mathrm{R} \& \mathrm{D}$ lab by solving the following problem:

$$
\max _{L_{A, j}} E\left[\pi_{j}\right]=\rho_{j}\left(L_{B}, L_{A, j}\right) \pi(\bar{A})+\left(1-\rho_{j}\left(L_{B}, L_{A, j}\right)\right)(1-\sigma) \frac{1}{\gamma} \pi(\bar{A})-w L_{A, j},
$$

where we use $\pi(\bar{A})$ as a shorthand notation for the profits to be made by offering an intermediate good of quality $\bar{A}$ as given by (5). The first-order condition for an interior solution of the firm's problem is given by

$$
\frac{d \rho_{j}\left(L_{B}, L_{A, j}\right)}{d L_{A, j}} \pi(\bar{A})\left(1-\frac{1-\sigma}{\gamma}\right)-w=0 .
$$

Hence, we obtain

$$
L_{A, j}=\frac{1}{4}\left[\frac{\pi(\bar{A})}{w}\left(1-\frac{1-\sigma}{\gamma}\right)\right]^{2} \theta_{j} L_{B} .
$$

Inserting the optimal level of applied research back into (34) yields

$$
\begin{gathered}
\rho_{1}\left(L_{B}\right)=\min \left\{\theta(w) L_{B}, 1\right\}, \\
\rho_{2}\left(L_{B}\right)=\min \left\{\eta \theta(w) L_{B}, 1\right\},
\end{gathered}
$$

where $\theta(w)=\frac{1}{2} \frac{\pi(\bar{A})}{w}\left(1-\frac{1-\sigma}{\gamma}\right) \hat{\theta}$. The difference to (6) and (7) is that the marginal productivity of basic research now depends on the wage for skilled labor $w$ and other exogenous parameters, such as the innovative step $\gamma$ and openness $\sigma$.

The wage for skilled labor depending on the amount of basic research is determined by the market clearing condition for skilled labor:

$$
\bar{L}=L_{B}+s_{t-1} L_{A, 1}+\left(1-s_{t-1}\right) L_{A, 2}+\int_{0}^{1} L_{x}(i) d i .
$$

This equation does not yield a closed-form solution for $w\left(L_{B}\right)$. However, we can write the government's objective equivalently to (18) as $c=\left(\frac{\alpha^{2} \bar{A}_{t}}{w}\right)^{\frac{\alpha}{1-\alpha}} \zeta\left(L_{B}, w\right)$, where we adapt the function $\zeta$ by substituting $\theta$ through $\theta(w)$ to reflect the impact of applied research. In this way, we obtain for the first-order condition:

$$
\begin{aligned}
\frac{d c}{d L_{B}}= & -\frac{\alpha}{1-\alpha}\left(\frac{\alpha^{2} \bar{A}_{t}}{w}\right)^{\frac{\alpha}{1-\alpha}} \frac{1}{w} \frac{d w}{d L_{B}} \zeta\left(L_{B}\right)+\left(\frac{\alpha^{2} \bar{A}_{t}}{w}\right)^{\frac{\alpha}{1-\alpha}} \frac{\partial \zeta\left(L_{B}, w\right)}{\partial w} \frac{d w}{d L_{B}} \\
& +\left(\frac{\alpha^{2} \bar{A}_{t}}{w}\right)^{\frac{\alpha}{1-\alpha}}\left[\frac{\partial s_{1, t}}{\partial L_{B}}+\frac{\partial s_{2, t}}{\partial L_{B}} \frac{1}{\gamma}+\frac{\partial s_{f, t}}{\partial L_{B}}(1-\alpha(1-\alpha))\right] .
\end{aligned}
$$

$\overline{38}$ It is also possible to formulate patent races with a finite number of contestants. 
In analogy to the decomposition in Sect. 4, the Labor Cost Effect now comprises the first two summands of (41), while the two other effects can be written as in (24) and (25) when substituting $\theta$ by $\theta(w)$. As $\theta(w)$ is a declining function of $w, \frac{\partial \zeta\left(L_{B}, w\right)}{\partial w}$ is negative, while we still expect $\frac{d w}{d L_{B}}$ to be positive. Hence, by including applied R\&D, the labor costs of basic research increase, which tends to reduce optimal basic-research levels compared to the basic model version. Moreover, as $\theta(w)$ is a declining function, $\rho_{j}\left(L_{B}\right)$ tends to be a concave rather than a linear function in $L_{B}$. Hence, the linear approximation may underestimate the productivity of basic research at low levels of $L_{B}$, while tending to overestimate it at higher levels. The bottom line is that if we include private, applied R\&D in the model, we can identify the same effects, but their magnitudes change.

\section{E Empirical Appendix}

In this appendix, we first provide estimation results of fixed effects and random effects regressions models as in Sect. 8, but with foreign direct investment data from WDI to reflect openness. ${ }^{39}$ Thereafter, we present the results of a two-stage-least-squares estimation of the random effects model using one period lags of the variables growth, openness, and distance to the frontier as instruments for their non-lagged counterparts.

Table 5 shows the results of the regressions conducted in Sect. 8 but with the sum of foreign direct investment in- and outflows as a measure of openness. The coefficients possess the same signs as in the regressions presented in Sect. 8 and as expected from the theory. The interaction between openness and growth plays an important role as shown in columns (2) and (3) of Table 5, which display the estimation results of the fixed effects and the random effects model with the interaction term between openness and growth. In both cases the coefficient of the interaction term is significant at the $5 \%$-level, with a $p$ value in the random effects model slightly higher than 0.01 at 0.017 . However, when only using FDI as openness measure, we observe in the first column that openness is also significant in the fixed effects regression model without the interaction term between openness and growth.

Again a Hausman-test does not reject that differences between the coefficients in the fixed effects and the random effects model are statistically significant. Consequently, we can use the random-effects model and include the time-invariant controls. The results are shown in columns (4) and (5). In this case, openness is not significant when the interaction term is left out (see col. (4)). Both the coefficient of the interaction term $\beta_{3}$ and that of openness $\beta_{2}$ become jointly significant at the $10 \%$ level when the interaction term is added. The $p$ values of $\beta_{2}$ and $\beta_{3}$ are 0.069 and 0.087 , respectively, and joint significance is at a $p$ value of 0.089 .

Next we present the two-stage least squares estimation results of the random effects model with one-period lags as instruments for the variables growth, openness, and distance to the technological frontier. The first stage results are depicted in the Table 6.

Joint significance of log growth gr-1 $_{t}, \log$ openness $_{t-1}, \log$ openness $_{t-1} * \log$ growth $_{t-1}$ and $\log$ frontier $_{t-1}$ in all four reduced from regressions is given in $F$ tests with $p<0.01$. Additionally, the Kleibergen-Paap LM test of the rank of the matrix rejects $\mathrm{H}_{0}$ : Rank of matrix is

\footnotetext{
39 We use the sum of net FDI inflows and net FDI outflows. The inflows are defined as follows: "Foreign direct investment are the net inflows of investment to acquire a lasting management interest (10\% or more of voting stock) in an enterprise operating in an economy other than that of the investor. It is the sum of equity capital, reinvestment of earnings, other long-term capital, and short-term capital as shown in the balance of payments. This series shows net inflows (new investment inflows less disinvestment) in the reporting economy from foreign investors. Data in percentage of GDP" (World Bank 2010). The outflows are defined accordingly.
} 
Table 5 Estimation results when openness is reflected by FDI

\begin{tabular}{|c|c|c|c|c|c|}
\hline & \multicolumn{5}{|c|}{ Log basic research expenditures/GDP } \\
\hline & $\begin{array}{l}(1) \\
\mathrm{FE}\end{array}$ & $\begin{array}{l}(2) \\
\mathrm{FE}\end{array}$ & $\begin{array}{l}(3) \\
\mathrm{RE}\end{array}$ & $\begin{array}{l}(4) \\
\mathrm{RE}\end{array}$ & $\begin{array}{l}(5) \\
\mathrm{RE}\end{array}$ \\
\hline Log growth & $\begin{array}{l}0.034 \\
(0.043)\end{array}$ & $\begin{array}{l}0.127 * * \\
(0.058)\end{array}$ & $\begin{array}{l}0.134 * * \\
(0.059)\end{array}$ & $\begin{array}{l}-0.011 \\
(0.044)\end{array}$ & $\begin{array}{l}0.080 \\
(0.073)\end{array}$ \\
\hline Log openness (FDI) & $\begin{array}{l}0.073 * * * \\
(0.023)\end{array}$ & $\begin{array}{l}0.146^{* * * *} \\
(0.036)\end{array}$ & $\begin{array}{l}0.149 * * * \\
(0.035)\end{array}$ & $\begin{array}{l}0.014 \\
(0.057)\end{array}$ & $\begin{array}{l}0.073 * \\
(0.040)\end{array}$ \\
\hline Log openness $(\mathrm{FDI}) * \log$ growth & & $\begin{array}{l}-0.095 * * \\
(0.042)\end{array}$ & $\begin{array}{l}-0.104 * * \\
(0.044)\end{array}$ & & $\begin{array}{l}-0.086 * \\
(0.050)\end{array}$ \\
\hline Log distance to frontier & $\begin{array}{l}0.293 \\
(0.231)\end{array}$ & $\begin{array}{l}0.408 * \\
(0.222)\end{array}$ & $\begin{array}{l}0.464 * * * \\
(0.110)\end{array}$ & $\begin{array}{l}0.326^{*} \\
(0.192)\end{array}$ & $\begin{array}{l}0.333^{*} \\
(0.200)\end{array}$ \\
\hline Share of population & -0.003 & 0.004 & 0.014 & 0.004 & 0.005 \\
\hline w. tertiary education & $(0.014)$ & $(0.013)$ & $(0.009)$ & $(0.011)$ & $(0.012)$ \\
\hline Time-invar. controls & No & No & No & Yes & Yes \\
\hline$R^{2}$ & 0.539 & 0.575 & 0.392 & 0.691 & 0.699 \\
\hline$N$ & 81 & 81 & 81 & 69 & 69 \\
\hline
\end{tabular}

Notes: In all regressions we controlled for time trends and periodic effects via time dummies. Controlling only for either of the two does not affect the results substantially. Standard error estimates are cluster robust (cluster is country) and reported in parentheses

*** Significant at the $1 \%$ level

** Significant at the $5 \%$ level

* Significant at the $10 \%$ level

Table 6 First-stage results

\begin{tabular}{|c|c|c|c|c|}
\hline & Log growth & Log openness & Log openness $* \log$ growth & Log frontier \\
\hline Log growth $t-1$ & $\begin{array}{l}6.408 \\
(4.490)\end{array}$ & $\begin{array}{l}0.487 * * \\
(0.236)\end{array}$ & $\begin{array}{l}25.573 \\
(19.288)\end{array}$ & $\begin{array}{l}-0.057 \\
(1.261)\end{array}$ \\
\hline $\log _{\text {openness }} t-1$ & $\begin{array}{l}1.549 * \\
(0.870)\end{array}$ & $\begin{array}{l}0.909 * * * \\
(0.082)\end{array}$ & $\begin{array}{l}6.944 * \\
(3.628)\end{array}$ & $\begin{array}{l}-0.038 \\
(0.293)\end{array}$ \\
\hline $\log _{\text {openness }}+1 * \log$ growth $_{t-1}$ & $\begin{array}{l}-1.642 \\
(1.079)\end{array}$ & $\begin{array}{l}-0.120 * * \\
(0.057)\end{array}$ & $\begin{array}{l}-6.589 \\
(4.640)\end{array}$ & $\begin{array}{l}0.019 \\
(0.301)\end{array}$ \\
\hline Log distance to frontier ${ }_{t-1}$ & $\begin{array}{l}-0.498 * * * \\
(0.166)\end{array}$ & $\begin{array}{l}-0.037 * * * \\
(0.012)\end{array}$ & $\begin{array}{l}-2.112 * * * \\
(0.714)\end{array}$ & $\begin{array}{l}0.876 * * * \\
(0.047)\end{array}$ \\
\hline Pop with tert educ & $\begin{array}{l}0.023 \\
(0.035)\end{array}$ & $\begin{array}{l}-0.003 \\
(0.004)\end{array}$ & $\begin{array}{l}0.106 \\
(0.154)\end{array}$ & $\begin{array}{l}-0.008 \\
(0.006)\end{array}$ \\
\hline Time invariant controls & Yes & Yes & Yes & Yes \\
\hline$N$ & 48 & 48 & 48 & 48 \\
\hline
\end{tabular}

Notes: Random effects model is used in all four regressions. In all regressions we controlled for time trends and periodic effects via time dummies. Standard error estimates are cluster robust (cluster is country) and reported in parentheses

$* * *$ Significant at the $1 \%$ level

** Significant at the $5 \%$ level

* Significant at the $10 \%$ level 
Table 7 Second-stage results

Log basic research expenditures/GDP

\begin{tabular}{ll}
\hline Log growth & 3.693 \\
Log openness & $(0.196)$ \\
& 2.305 \\
Log openness * $\log$ growth & $(0.137)$ \\
& -0.860 \\
Log distance to frontier & $(0.203)$ \\
& 0.083 \\
Pop tert. education & $(0.945)$ \\
Time-invariant controls & 0.003 \\
Time dummies & $(0.866)$ \\
$N$ & Yes \\
\hline
\end{tabular}

Notes: Random effects model with one period lagged instruments for log growth, log openness, log openness* $\log$ growth, and $\log$ frontier. The $p$ values are reported in parentheses

3 (lower than full rank $=4$ ) at $p$ value of $0.022 .^{40}$ This indicates that our instruments have explanatory power across all reduced forms.

Table 7 gives the second-stage results.

In Table 7, we present the $p$ values in parentheses. As already discussed in the main text, the signs of $\beta_{2}$ and $\beta_{3}$ are in line with our theoretical predictions, but the $p$ values are at 0.2 for the interaction term of openness and growth and slightly lower for openness.

\section{References}

Acs, Z. J., Audretsch, D. B., \& Feldmann, M. (1992). Real effects of academic research: Comment. The American Economic Review, 82, 363-367.

Acs, Z. J., Audretsch, D. B., \& Feldmann, M. (1994). R\&d spillovers and recipient firm size. Review of Economics and Statistics, 76, 336-340.

Adams, J. D. (1990). Fundamental stocks of knowledge and productivity growth. Journal of Political Economy, 98(4), 673-702.

Aghion, P., Blundell, R., Griffith, R., Howitt, P., \& Prantl, S. (2009). The effects of entry on incumbent innovation and productivity. The Review of Economics and Statistics, 91(1), 20-32.

Aghion, P., \& Howitt, P. (1992). A model of growth through creative destruction. Econometrica, 60(2), 323351.

Aghion, P., \& Howitt, P. (1996). Research and development in the growth process. Journal of Economic Growth, 1(1), 49-73.

Alfaro, L., Chanda, A., Kalemli-Ozcan, S., \& Sayek, S. (2010). Does foreign direct investment promote economic growth? Exploring the role of financial markets on linkages? Journal of Development Economics, 91, 242-256.

Almeida, P. (1996). Knowledge sourcing by foreign multinationals: Patent citation analysis in the us semiconductor industry. Strategic Management Journal, 17, 155-165.

40 The test statistic is robust to heteroskedasticity and clustering on country. Also, the Kleibergen-Paap Wald test of the rank of the matrix rejects $\mathrm{H}_{0}$ : Rank of matrix is 3 (lower than full rank $=4$ ) at $p$ value of 0.0025 . Again, the test statistic is robust to heteroskedasticity and clustering on country. 
Amon, C. (2011). Basic and applied research in the process of innovation-A review of the literature. Mimeo, ETH Zurich.

Arnold, L. G. (1997). Basic and applied research. Finanzarchiv, 54, 169-186.

Baily, M., \& Gersbach, H. (1995). Efficiency in manufacturing and the need for global competition. Brookings Papers on Economic Activity. Microeconomics, 1995, 307-358.

Bania, N., Eberts, R. W., \& Fogarty, M. S. (1993). Universities and the startup of new companies: Can we generalize from Route 128 and Silicon Valley?The Review of Economics and Statistics, 75(4), 761-766.

Barro, R., \& Lee, J.-W. (2010). A new data set of educational attainment in the world, 1950-2010. NBER Working Paper No. 15902.

Blankenau, W., Cassou, S., \& Ingram, B. (2007). Allocating government education expenditures across k-12 and college education. Economic Theory, 31(1), 85-112.

Caucutt, E. M., \& Kumar, K. B. (2003). Higher education subsidies and heterogeneity: a dynamic analysis. Journal of Economic Dynamics and Control, 27(8), 1459-1502.

Cozzi, G., \& Galli, S. (2009). Science-based R\&D in Schumpeterian growth. Scottish Journal of Political Economy, 56, 474-491.

Cozzi, G., \& Galli, S. (2011a). Privatization of knowledge: Did the U.S. get it right? MPRA Paper 29710.

Cozzi, G., \& Galli, S. (2011b). Upstream innovation protection: Common law evolution and the dynamics of wage inequality. MPRA Paper 31902.

Dreher, A. (2006). Does globalization affect growth? evidence from a new index of globalization. Applied Economics, 38(10), 1091-1110. Updated in Dreher, Axel, Noel Gaston and Pim Martens (2008), Measuring Globalization-Gauging its Consequences (New York: Springer).

Gersbach, H., Schneider, M., \& Schneller, O. (2010). Optimal mix of applied and basic research, distance to frontier, and openness. CEPR Discussion Paper 7795, Centre for Economic Policy Research, London.

Gersbach, H., Sorger, G., \& Amon, C. (2009). Hierarchical growth: Basic and applied research. CER-ETH Working Papers 118, CER-ETH-Center of Economic Research at ETH Zurich.

Grilliches, Z. (1986). Productivity, R\&D, and basic research at the firm level in the 1970's. American Economic Review, 76(1), 141-154.

Huizinga, H., \& Laeven, L. (2008). International profit shifting within multinationals: A multi-country perspective. Journal of Public Economics, 92(5-6), 1164-1182.

Jaffe, A.B. (1989). Real effects of academic research. American Economic Review, 79(5), 957-970

Keller, W., \& Yeaple, S. R. (2009). Multinational enterprises, international trade, and productivity growth: Firm-level evidence from the united states. Review of Economics and Statistics, 91, 821-831.

Kuemmerle, W. (1999). The drivers of foreign direct investment into research and development: An empirical investigation. Journal of International Business Studies, 30(1), 1-24.

Link, A. N., \& Rees, J. (1990). Firm size, university based research, and the returns to r\&d. Small Business Economics, 2(1), 25-31.

Mansfield, E. (1991). Academic research and industrial invovation. Research Policy, 20(1), 1-12.

Mansfield, E. (1995) Academic research underlying industrial innovation: Sources, characteristics, and financing. Review of Economics and Statistics, 77(1), 55-65.

Mansfield, E. (1998). Academic research and industrial innovation: An update of empirical findings. Research Policy, 26(7-8), 773-776.

Melitz, M. J. (2003). The impact of trade on intra-industry reallocations and aggregate industry productivity. Econometrica, 71(6), 1695-1725.

Nelson, R. R. (1986). Institutions supporting technical advance in industry. American Economic ReviewPapers and Proceedings, 76(2), 186-189.

Nelson, R. R. (2012). Some features of research by economists of technological change foreshadowed by the rate and direction of inventive activity revisited. In J. Lerner, \& S. Stern (Eds.), The Rate and Direction of Inventive Activity Revisited (pp. 35-41) National Bureau of Economic Research

OECD. (2010). Main Science and Technology Indicators, volume 2010(1).

OECD. (2012). OECD science, technology and R\&D statistics. http://www.oecd-ilibrary.org/ science-and-technology/data/oecd-science-technology-and-r-d-statistics_strd-data-en.

Park, W. G. (1998). A theoretical model of government research and growth. Journal of Economic Behavior \& Organization, 34(1), 69-85.

Weichenrieder, A. (2009). Profit shifting in the EU: Evidence from Germany. International Tax and Public Finance, 16(3), 281-297.

World Bank. (2010). World development indicators. 2010.

Zucker, L. G., Darby, M. R., \& Brewer, M. B. (1998). Intellectual human capital and the birth of U.S. biotechnology enterprises. American Economic Review, 88(1), 290-306. 